\title{
Association of Changes in Norepinephrine and Serotonin Transporter Expression with the Long-Term Behavioral Effects of Antidepressant Drugs
}

\author{
Zaorui Zhao*, ${ }^{, 1,2}$, Han-Ting Zhang ${ }^{2,3}$, Elianna Bootzin ${ }^{2,3}$, Mark J Millan ${ }^{4}$ and James M O'Donnell ${ }^{2,3}$ \\ 'Graduate Program in Pharmaceutical and Pharmacological Sciences, West Virginia University Health Sciences Center, Morgantown, WV, USA; \\ ${ }^{2}$ Department of Behavioral Medicine and Psychiatry, West Virginia University Health Sciences Center, Morgantown, WV, USA; ${ }^{3}$ Department of \\ Neurobiology and Anatomy, West Virginia University Health Sciences Center, Morgantown, WV, USA; ${ }^{4}$ Psychopharmacology Department, Institut \\ de Recherches Servier, Croissy/Seine, France
}

\begin{abstract}
Previous work has shown that repeated desipramine treatment causes downregulation of the norepinephrine transporter (NET) and persistent antidepressant-like effects on behavior, ie effects observed 2 days after discontinuation of drug treatment when acute effects are minimized. The present study examined whether this mechanism generalizes to other antidepressants and also is evident for the serotonin transporter (SERT). Treatment of rats for 14 days with $20 \mathrm{mg} / \mathrm{kg}$ per day protriptyline or $7.5 \mathrm{mg} / \mathrm{kg}$ per day sertraline reduced NET and SERT expression, respectively, in cerebral cortex and hippocampus; these treatments also induced a persistent antidepressantlike effect on forced-swim behavior. Increased serotonergic neurotransmission likely mediated the behavioral effect of sertraline, as it was blocked by inhibition of serotonin synthesis with p-chlorophenylalanine; a parallel effect was observed previously for desipramine and noradrenergic neurotransmission. Treatment with $20 \mathrm{mg} / \mathrm{kg}$ per day reboxetine for 42, but not I4, days reduced NET expression; antidepressant-like effects on behavior were observed for both treatment durations. Treatment for 14 days with $70 \mathrm{mg} / \mathrm{kg}$ per day venlafaxine, which inhibits both the NET and SERT, or $10 \mathrm{mg} / \mathrm{kg}$ per day phenelzine, a monoamine oxidase inhibitor, produced antidepressant-like effects on behavior without altering NET or SERT expression. For all drugs tested, reductions of NET and SERT protein were not accompanied by reduced NET or SERT mRNA in locus coeruleus or dorsal raphe nucleus, respectively. Overall, the present results suggest an important, though not universal, role for NET and SERT regulation in the long-term behavioral effects of antidepressants. Understanding the mechanisms underlying transporter regulation in vivo may suggest novel targets for the development of antidepressant drugs.

Neuropsychopharmacology (2009) 34, |467- I48I; doi:I0.1038/npp.2008.I83; published online I5 October 2008
\end{abstract}

Keywords: antidepressant drugs; norepinephrine transporter; serotonin transporter; p-chlorophenylalanine

\section{INTRODUCTION}

Antidepressants, in general, enhance noradrenergic and/or serotonergic neurotransmission following acute administration (Millan, 2006). For many antidepressants, including the tricyclic antidepressants, serotonin reuptake inhibitors (SRIs), norepinephrine reuptake inhibitors (NRIs), and serotonin-norepinephrine reuptake inhibitors (SNRIs), this results from inhibition of the norepinephrine or serotonin transporters (NET, SERT), which clear the transmitters from the synapse (Beyer et al, 2002; Katz et al, 2004; Morilak and Frazer, 2004; White et al, 2005). Some drugs enhance

\footnotetext{
*Correspondence: Dr Z Zhao, Department of Psychology, Yale University, 2 Hillhouse Avenue, PO Box 208205, New Haven, CT 06520, USA, Tel: + I 203432 0228, Fax: + I 203432 7172,

E-mail: zaorui.zhao@yale.edu

Received II July 2008; revised 4 September 2008; accepted 15 September 2008
}

monoaminergic neurotransmission by other mechanisms such as inhibition of monoamine oxidase (Laux et al, 1995; López-Muñoz et al, 2007) or antagonism of presynaptic $\alpha-2$ adrenergic receptors (Charney et al, 1986; Dickinson, 1990; Millan et al, 2000; Artigas et al, 2001). Although enhanced monoaminergic neurotransmission appears to be an effect shared by antidepressants from different chemical and pharmacological classes, its relationship to antidepressant efficacy is unclear as therapeutic effects develop gradually over time with repeated treatment (Frazer and Benmansour, 2002; Nelson et al, 2004; Katz et al, 2004).

This delayed clinical activity has raised questions regarding the relevance of the acute neurochemical effects of antidepressants, including enhancement of monoaminergic neurotransmission, to their long-term effects on behavior. It is believed that enhanced monoaminergic neurotransmission is not sufficient to produce an antidepressant effect, as this neurochemical effect is manifested 
early, before development of a clear, clinical effect. However, enhanced monoaminergic activity appears to be necessary for clinical activity. This is evident from the finding that inhibition of synthetic enzymes for norepinephrine (NE) or serotonin results in a rapid return of symptoms in depressed patients who have been treated successfully with desipramine or fluoxetine (Charney, 1998; Miller et al, 1996b). Recent work has implicated antidepressant-induced downregulation of NET and SERT in the brain as a mechanism that may contribute to the longterm pharmacological effects of antidepressant drugs (Hirano et al, 2005a; Thakker et al, 2005; Zhao et al, 2008). Reduced NET or SERT expression would increase monoaminergic neurotransmission, even in the absence of pharmacological inhibition of the transporters.

In a recent study, it was found that repeated treatment with desipramine, which is relatively selective for inhibition of the NET relative to the SERT, reduces the expression of the NET in cerebral cortex and hippocampus in a dosedependent manner (Zhao et al, 2008). This was evidenced by reduced binding of ${ }^{3} \mathrm{H}$-nisoxetine and by SDS-PAGE/ immunoblotting using NET-specific antisera. The reduced expression results in reduced uptake of ${ }^{3} \mathrm{H}$-norepinephrine into tissue slices in vitro and increased extracellular $\mathrm{NE}$ concentration in the prefrontal cortex measured in vivo using microdialysis. At all desipramine treatment conditions when the NET was found to be downregulated, an antidepressant-like effect on behavior was evident in the forced-swim test. Importantly, NET downregulation and behavioral effects were observed even when brain and plasma levels of desipramine and its major, active metabolite desmethyldesipramine were not detectable; ie these effects were persistent in that they were observed under conditions when behavioral effects due to acute drug action were minimized (Zhao et al, 2008). Finally, as is observed in the clinical setting (Lam et al, 2001; Miller et al, 1996b), the persistent antidepressant-like effect of desipramine in the forced-swim test was lost when tyrosine hydroxylase was inhibited with $\alpha$-methyl-p-tyrosine (AMPT; Zhao et al, 2008).

Other studies have reported that repeated treatment with antidepressant drugs reduces the expression of the NET in the brain (Benmansour et al, 2004; Wong et al, 2000). Similarly, some antidepressants, including SRIs, have been reported to reduce the expression of the SERT (Benmansour et al, 1999, 2002; Gould et al, 2003, 2006; Hirano et al, $2005 \mathrm{a}, \mathrm{b})$, resulting in enhanced serotonergic neurotransmission. Antidepressant-induced downregulation of the NET and SERT has been observed with cell lines in vitro (Zhu and Ordway, 1997; Zhu et al, 1998; Horschitz et al, 2001; Zhu et al, 2005; Iceta et al, 2007). This suggests that the downregulation may result from a direct effect of the drugs on the transporter and is not secondary to increased extracellular concentrations of the transmitter. Thus, NET and SERT downregulation may be effects caused by reuptake inhibitors and not by drugs that increase monoaminergic neurotransmission by other mechanisms, such as inhibition of monoamine oxidase.

Although it appears that NET and SERT downregulation with chronic treatment is an effect shared by a number of antidepressant drugs that inhibit monoamine reuptake, it is not clear to what extent this action contributes to the long- term behavioral effects of antidepressants from different pharmacological classes; to date, this relationship has been only investigated for desipramine. The present study examined the effects of the antidepressants protriptyline, reboxetine, sertraline, venlafaxine, and phenelzine on the NET and SERT and assessed whether changes in their expression resulted in antidepressant-like effects on behavior, similar to what has been observed with desipramine (Zhao et al, 2008). Protriptyline, a tricyclic antidepressant, produces neurochemical and behavioral effects similar to those of desipramine (Crissman and O'Donnell, 2002; O'Donnell et al, 2005). Reboxetine is an NRI that exhibits somewhat greater selectivity for the NET $v s$ the SERT compared to desipramine and protriptyline (Scates and Doraiswamy, 2000; Wong et al, 2000; Iversen, 2006). Sertraline is an SRI and is active in a number of antidepressant models (Benmansour et al, 1999, 2002). Venlafaxine, although classified as an SNRI, exhibits markedly greater potency for inhibition of the SERT than the NET (Iversen, 2006; Frazer, 2001). Phenelzine, a monoamine oxidase inhibitor, does not interact directly with the NET or SERT, but increases monoaminergic neurotransmission and has antidepressant activity (Thase et al, 1995). Overall, the present study shows that downregulation of the NET or SERT is produced by some antidepressants that interact with the transporters and that this effect contributes to their behavioral effects; however, persistent antidepressant-like effects on behavior can, in some cases, be observed even when NET or SERT expression is not altered.

\section{MATERIALS AND METHODS}

\section{Animals}

Male Sprague-Dawley rats (Harlan, Indianapolis, IN), weighing $300-350 \mathrm{~g}$, were housed two per cage in a temperature-controlled room $\left(22-23^{\circ} \mathrm{C}\right)$ with a $12 / 12-\mathrm{h}$ light-dark cycle (lights on at 0600 hours). Food and water were freely provided. Blind observations were used throughout all behavioral testing, which was carried out from 1300 to 1700 hours in a quiet room. All procedures were reviewed and approved by the Animal Care and Use Committee of West Virginia University Health Sciences Center, and are consistent with the NIH Guidelines for the Care and Use of Laboratory Animals (NIH publication no. 80-23, revised 1996).

\section{Drugs Administration}

Rats were anesthetized with ketamine $(100 \mathrm{mg} / \mathrm{kg})$ and xylazine $(10 \mathrm{mg} / \mathrm{kg})$ and implanted subcutaneously with osmotic minipumps (model 2ML2 or 2ML4; Alzet Corporation, Palo Alto, CA) preloaded with either vehicle (50\% saline, $40 \%$ DMSO, and 10\% ethanol), protriptyline (SigmaAldrich, St Louis, MO), reboxetine (provided by Institut de Recherches Servier, Croissy/Seine, France), sertraline (Tocris, Ellisville, MO), or venlafaxine (Sigma-Aldrich) at concentrations that delivered 10 or 20 (protriptyline), 20 (reboxetine), 7.5 (sertraline), or 70 (venlafaxine) $\mathrm{mg} / \mathrm{kg}$ per day of the free base. Minipumps were removed, under anesthesia, 14 days later. However, for some rats treated 
with reboxetine, minipumps were removed 21 days after implantation and new minipumps were implanted, providing 42 days of drug administration. A dose of $10 \mathrm{mg} / \mathrm{kg}$ per day (i.p.) of the irreversible monoamine oxidase inhibitor phenelzine was administrated for 14 days. Doses of each of the drugs used were chosen based on previous reports of neuropharmacological activity (Ordway et al, 1991; Gould et al, 2006).

Rats were tested for antidepressant-like behavior in the forced-swim test and locomotor activity in the open-field test 2 days after pump removal or the last phenelzine treatment; this was done to minimize acute drug effects on behavior (Zhao et al, 2008). However, the behavioral tests for one group of rats treated with $10 \mathrm{mg} / \mathrm{kg}$ per day protriptyline were performed 1 day after the removal of pumps. Following the completion of the behavioral tests, rats were killed by decapitation, their brains were removed, and cerebral cortex and hippocampus were dissected for measurement of NET and SERT using ${ }^{3} \mathrm{H}$-nisoxetine or ${ }^{3} \mathrm{H}$ citalopram binding and SDS-PAGE/immunoblotting with specific antisera. Also, locus coeruleus and raphe nucleus were punched from surrounding tissue for real-time PCR measurement of NET and SERT mRNA.

\section{Forced-Swim Test}

The forced-swim test, originally described by Porsolt $e t$ al (1977), was carried out as described by Zhao et al (2008); testing was carried out 2 days following the discontinuation of chronic antidepressant treatment (except for one protriptyline group; see above), to minimize acute drug effects on behavior. Plexiglas cylinders $(40 \mathrm{~cm}$ high and $18 \mathrm{~cm}$ in diameter) were filled with water $(30 \mathrm{~cm}$ depth, $22-$ $23^{\circ} \mathrm{C}$ ); at this depth, rats could not touch the bottom of the cylinder with their tails or hindlimbs. On day 1 (ie 1 day after cessation of antidepressant treatment), the rats were pretested for $15 \mathrm{~min}$ to develop an immobility posture after initial escape-oriented movements (Cryan et al, 2002). On day 2 (2 days after cessation of chronic antidepressant treatment), rats were subjected to the 5 -min forced-swim test and immobility time was recorded; immobility was defined as floating on the surface of the water with the only movement being that required to keep the head above water. Some rats treated with $10 \mathrm{mg} / \mathrm{kg}$ per day protriptyline were subjected to 5 -min forced-swim testing 1 day after the end of the antidepressant treatment regimen, with the 15min pretest on the last day of drug treatment. Finally, in some tests, rats were administered the tryptophan hydroxylase inhibitor $p$-chlorophenylalanine (PCPA, $300 \mathrm{mg} / \mathrm{kg}$, i.p; Sigma-Aldrich) twice daily for 3 consecutive days, with the last dose given $18 \mathrm{~h}$ before 5 -min forced-swim test. This was done to determine whether reduced serotonergic neurotransmission blocked the antidepressant-like effect observed in the forced-swim test following downregulation of the SERT; this paralleled previous experiments examining the effects of reduced noradrenergic neurotransmission on persistent antidepressant-like behavior observed following desipramine-induced downregulation of the NET (Zhao et al, 2008).

To ensure that any changes in immobility in the forcedswim test were not secondary to increased locomotor activity, rats were observed in the open-field test (Zhang et al, 2008). The floor of the open-field apparatus was divided into nine identical squares. Rats were placed individually in the center and allowed to explore for $5 \mathrm{~min}$; the number of line crossings (with all four paws crossing a line) and rears were recorded. None of the treatments increased locomotor activity, so these data are not shown.

\section{SDS-PAGE/Immunoblotting of SERT and NET Protein in the Rat Brain}

Cerebral cortex and hippocampus were homogenized in TEVP buffer ( $10 \mathrm{mM}$ Tris base, $5 \mathrm{mM} \mathrm{NaF}, 1 \mathrm{mM} \mathrm{Na}_{3} \mathrm{VO}_{4}$, $1 \mathrm{mM}$ EDTA, $1 \mathrm{mM}$ EGTA, $320 \mathrm{mM}$ sucrose; $\mathrm{pH}$ 7.4) with a glass homogenizer and centrifuged at $1000 \mathrm{~g}$ for $20 \mathrm{~min}$ at $4{ }^{\circ} \mathrm{C}$. The supernatant was centrifuged at $20000 \mathrm{~g}$ for $30 \mathrm{~min}$ to obtain a crude synaptosomal fraction (Lin et al, 1998; Wyszynski et al, 1998; Dunah and Standaert, 2001). The pellets were resuspended and solubilized with RIPA buffer (50 mM Tris, $150 \mathrm{mM} \mathrm{NaCl,} \mathrm{2 \%} \mathrm{IGEPAL} \mathrm{CA-630,} \mathrm{0.5 \%}$ sodium deoxycholate, $0.1 \%$ SDS, and $0.1 \%$ Triton X-100; $\mathrm{pH}$ 8.0) containing protease inhibitors (Roche, Indianapolis, IN). Protein content of membrane lysate was measured using the bicinchoninic acid assay (Smith et al, 1985; Pierce, Rockford, IL). Equal amounts of protein from both control and treated rats were mixed with $2 \times$ Laemmli sample buffer (Bio-Rad, Hercules, CA) and boiled at $100^{\circ} \mathrm{C}$ for $3 \mathrm{~min}$. Samples were loaded onto $8 \%$ polyacrylamide gels for electrophoresis and, after separation, transferred to nitrocellulose membranes. The membranes were blocked in TBST buffer containing $5 \%$ non-fat milk for $2 \mathrm{~h}$ at room temperature, washed with TBST buffer, and incubated overnight at $4{ }^{\circ} \mathrm{C}$ with a specific, rabbit polyclonal antibody generated against a unique 22 amino-acid peptide sequence mapping to the first extracellular domain of the NET (Chemicon, Temecula, CA; Zhao et al, 2008) or a peptide fragment of the C terminus of the SERT (Santa Cruz, Santa Cruz, CA; Xie et al, 2006). After washing with TBST, membranes were incubated for $1 \mathrm{~h}$ at room temperature with horseradish peroxidase-conjugated goat anti-rabbit immunoglobulin G (Pierce). The labeled protein bands were detected by chemiluminescence imaging (Bio-Rad) and quantified by densitometry using an NIH image analysis program, and normalized to actin. Comparisons of treatment effects were carried out within single gels/immunoblots.

\section{${ }^{3} \mathrm{H}$-Nisoxetine Binding Assay}

${ }^{3} \mathrm{H}$-Nisoxetine binding to the NET was carried out as described previously (Tejani-Butt et al, 1990; Bryan-Lluka et al, 2001). One-half of the cerebral cortex or hippocampus was homogenized in $5 \mathrm{ml}$ of ice-cold binding buffer $(50 \mathrm{mM}$ Tris base, $120 \mathrm{mM} \mathrm{NaCl}, 5 \mathrm{mM} \mathrm{KCl}$; $\mathrm{pH}$ 7.4) using a Polytron (Brinkman Instruments, Westbury, NY) and then centrifuged at $36000 \mathrm{~g}$ for $10 \mathrm{~min}$ at $4^{\circ} \mathrm{C}$. The supernatant was discarded, the pellet resuspended in ice-cold binding buffer, centrifuged at $36000 \mathrm{~g}$ for $10 \mathrm{~min}$ at $4^{\circ} \mathrm{C}$, and the pellet resuspended in binding buffer to obtain a protein concentration of $1 \mathrm{mg} / \mathrm{ml}$ as assayed using the bicinchoninic acid method (Smith et al, 1985; Pierce). Triplicate tubes containing $100 \mu \mathrm{l}$ incubation buffer (total binding) or $100 \mu \mathrm{l}$ desipramine (final concentration $50 \mu \mathrm{M}$; nonspecific bind- 
ing), $100 \mu \mathrm{l}$ tissue sample, and $50 \mu \mathrm{l}{ }^{3} \mathrm{H}$-nisoxetine (final concentration $5 \mathrm{nM} ; 72 \mathrm{Ci} / \mathrm{mmol}$, PerkinElmer, Boston, MA) were incubated in a shaking ice bath for $4 \mathrm{~h}$. Nonspecific binding (ie in the presence of $50 \mu \mathrm{M}$ desipramine) was approximately $10 \%$ of total binding. Bound ${ }^{3} \mathrm{H}$-nisoxetine was captured by rapid filtration through glass fiber filters (GF/B; Brandel, Gaithersburg, MD) that were presoaked in $5 \%$ polyethyleneimine under vacuum with a cell harvester (Brandel). Filters were washed twice with ice-cold binding buffer and radioactivity was determined by liquid scintillation counting.

\section{${ }^{3} \mathrm{H}$-Citalopram Binding Assay \\ ${ }^{3} \mathrm{H}$-Citalopram binding to the SERT was performed as described previously (D'Amato et al, 1987; Gould et al, 2006). One-half of the cerebral cortex or hippocampus was homogenized in $5 \mathrm{ml}$ of ice-cold binding buffer (50 mM Tris base, $120 \mathrm{mM} \mathrm{NaCl}, 5 \mathrm{mM} \mathrm{KCl} ; \mathrm{pH}$ 7.4) using a Polytron (Brinkman Instruments) and then centrifuged at $36000 \mathrm{~g}$ for $10 \mathrm{~min}$ at $4{ }^{\circ} \mathrm{C}$. The supernatant was discarded, the pellet was resuspended in ice-cold binding buffer, centrifuged at $36000 \mathrm{~g}$ for $10 \mathrm{~min}$ at $4{ }^{\circ} \mathrm{C}$, to obtain a protein concentration of $1 \mathrm{mg} / \mathrm{ml}$ as assayed using the bicinchoninic acid method (Smith et al, 1985; Pierce). Triplicate tubes containing $100 \mu \mathrm{l}$ incubation buffer (total binding) or $100 \mu$ l fluoxetine (final concentration $50 \mu \mathrm{M}$; nonspecific binding), $100 \mu \mathrm{l}$ tissue sample, and $50 \mu \mathrm{l}^{3} \mathrm{H}$-citalopram (final concentration $5 \mathrm{nM}$; $79 \mathrm{Ci} / \mathrm{mmol}$; PerkinElmer) were incubated for $1 \mathrm{~h}$ with shaking at room temperature. Nonspecific binding (ie in the presence of $50 \mu \mathrm{M}$ fluoxetine) was approximately $10 \%$ of total binding. Bound ${ }^{3} \mathrm{H}$-citalopram was captured by rapid filtration through glass fiber filters (GF/B; Brandel) that were presoaked in $5 \%$ polyethyleneimine under vacuum with a cell harvester (Brandel). Filters were washed twice with ice-cold binding buffer and radioactivity was deter- mined by liquid scintillation counting.}

\section{Measurement of NET and SERT mRNA by Quantitative Real-Time PCR}

Locus coeruleus (for NET mRNA) and dorsal and median raphe nucleus (for SERT mRNA) were punched from the rat brain (Chamas et al, 1999, 2004; Paxinos and Watson, 1998; Zhu et al, 2002). Total RNA was extracted using the Trizol reagent (Invitrogen, Carlsbad, CA) and was kept in RNAlater buffer (Ambion, Austin, TX) and stored at $-80^{\circ} \mathrm{C}$. Total RNA concentration was determined by spectrophotometry and adjusted to $0.5 \mu \mathrm{g} / \mu \mathrm{l}$. The quality of the RNA was verified using 1\% denaturing agarose gel electrophoresis. Contaminating genomic DNA was eliminated by incubating with DNase mixture (Qiagen, Valencia, $\mathrm{CA}$ ) at room temperature for $20 \mathrm{~min}$. RNA was reverse transcribed to cDNA with high-capacity cDNA archive kit (Applied Biosystems, Foster City, CA). The cDNA was subjected to real-time PCR using TaqMan universal PCR Master Mix and ABI 7300 real-time PCR system (Applied Biosystems). Specific primers and probes were purchased from predesigned, preoptimized TaqMan Gene Expression Assays (Applied Biosystems). Quantities of NET and SERT mRNA were normalized to the $18 \mathrm{~s}$ rRNA. Analyses were performed using ABI 7300 system SDS software.

\section{Statistical Analysis}

The data were analyzed by one-way analyses of variance followed by Tukey's or Bonferroni's post hoc tests. When simple, paired comparisons between two groups were conducted, two-tailed Student's $t$-tests were used. Data are presented as means \pm SEM and differences are considered statistically significant when $p$-values are less than 0.05 .

\section{RESULTS}

The neurochemical and behavioral effects of repeated antidepressant treatment were assessed 2 days after the end of the treatment period (ie osmotic minipump removal or discontinuation of phenelzine injections), except for some tests with protriptyline (see below). This permitted assessment of persistent effects under conditions when brain and plasma concentrations of drugs would be minimized (Zhao et al, 2008). None of the treatments increased locomotor activity, which could confound interpretation of results in the forced-swim tests; however, 1 day following treatment with protriptyline, locomotor activity was reduced (ie line crosses in the open-field test, to $65 \%$ of control; data not shown).

\section{Effects of Protriptyline}

The relationship between the effect of chronic protriptyline treatment on NET expression and its effect on behavior in the forced-swim test was examined. Overall, treatment of rats with protriptyline for 14 days reduced NET expression, as indicated by a reduction of the binding of ${ }^{3} \mathrm{H}$-nisoxetine to the NET in preparations of cerebral cortex $\left(\mathrm{F}_{(4,21)}=5.75\right.$, $p<0.01$; Figure 1a) and hippocampus $\left(\mathrm{F}_{(4,21)}=7.43\right.$, $p<0.001)$. Post hoc comparisons showed that 2 days following discontinuation of treatment with $20 \mathrm{mg} / \mathrm{kg}$ protriptyline, a significant reduction was observed only in cerebral cortex. Downregulation of the NET also was demonstrated using SDS-PAGE/immunoblotting of preparations of cerebral cortex $\left(\mathrm{F}_{(2,12)}=12.19, p<0.001\right.$; Figure $1 \mathrm{~b})$ and hippocampus $\left(\mathrm{F}_{(2,12)}=13.81, p<0.001\right.$; Figure 1b). Downregulation of NET expression was not observed 2 days following the end of treatment with $10 \mathrm{mg} / \mathrm{kg}$ per day protriptyline for 14 days, but was seen 1 day following this treatment (Figure 1a).

A persistent antidepressant-like effect in the forced-swim test was evident 2 days after discontinuation of 14-day treatment with $20 \mathrm{mg} / \mathrm{kg}$ per day protriptyline or 1 day after discontinuation of 14-day treatment with $10 \mathrm{mg} / \mathrm{kg}$ per day protriptyline $\left(\mathrm{F}_{(4,25)}=10.00, p<0.001\right.$; Figure $\left.1 \mathrm{c}\right)$; this paralleled the protriptyline-induced downregulation of the NET. No antidepressant-like effect on behavior was observed 2 days after chronic protriptyline treatment at a dose of $10 \mathrm{mg} / \mathrm{kg}$ per day (Figure 1c), consistent with the lack of NET downregulation at this treatment condition.

To determine whether the downregulation of the NET resulted from a change in gene transcription, NET mRNA expression in the locus coeruleus was measured by quantitative RT-PCR. The normalized, relative NET mRNA expression was not changed 2 days following the end of chronic treatment with $20 \mathrm{mg} / \mathrm{kg}$ per day protriptyline or 

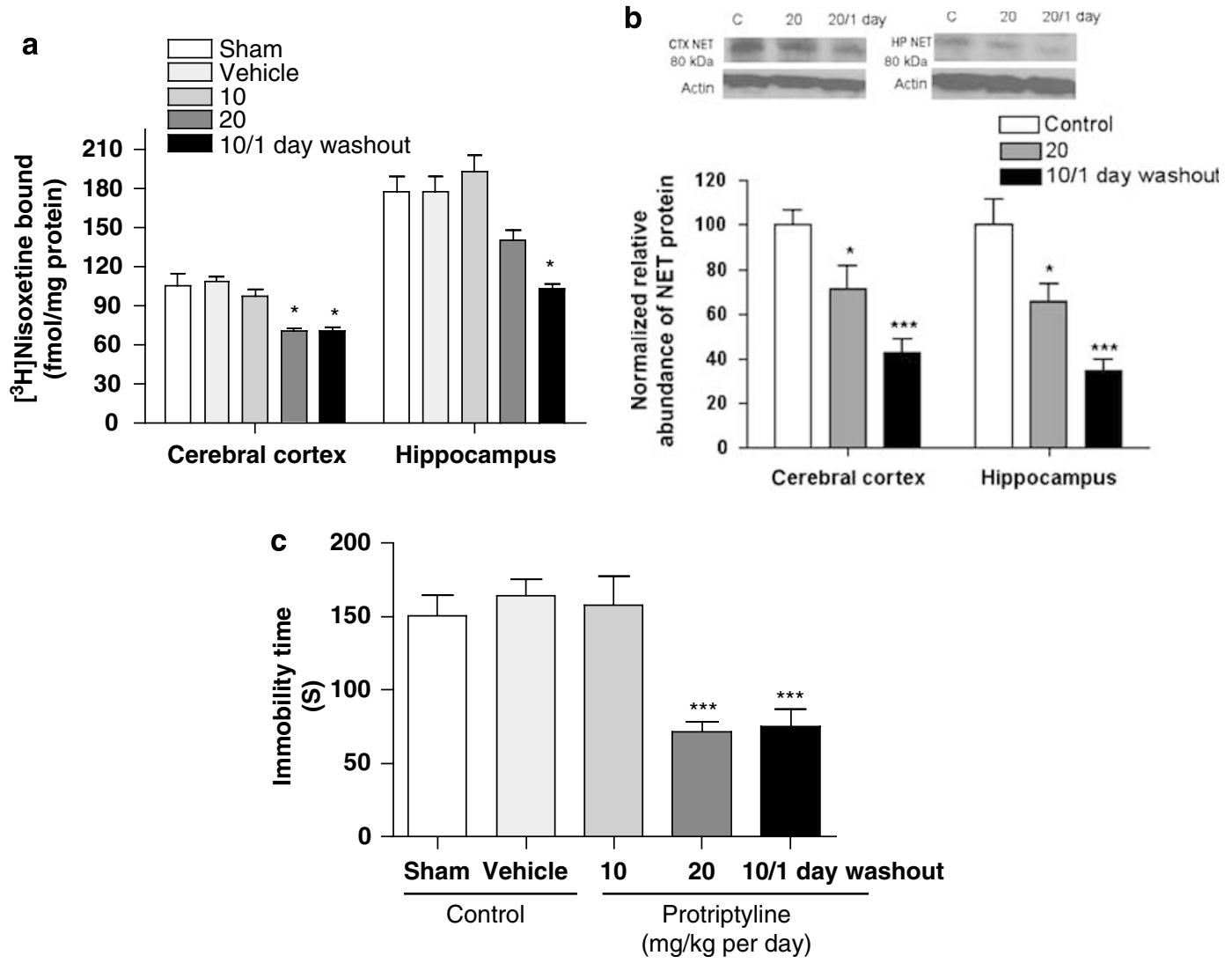

Figure I Chronic treatment with protriptyline $\left(10,20 \mathrm{mg} / \mathrm{kg}\right.$ ) for 2 weeks reduced norepinephrine transporter (NET) expression, determined by ${ }^{3} \mathrm{H}$ nisoxetine binding (a) and SDS-PAGE/immunoblotting (b), and reduced immobility time in the forced-swim test (c). All measures were determined 2 days after the end of the chronic treatment period, except one group $(10 \mathrm{mg} / \mathrm{kg}$ per day with I day washout). Data shown are means \pm SEM of 5-8 rats per group. $* p<0.05, * * * * 0.00$ I vs control.

1 day following the end of chronic treatment with $10 \mathrm{mg} / \mathrm{kg}$ per day protriptyline $\left(\mathrm{F}_{(2,27)}=2.14, p>0.05\right.$; Table 1$)$. Similarly, repeated treatment with $15 \mathrm{mg} / \mathrm{kg}$ per day desipramine, which reduces NET protein expression (Zhao et al, 2008), also did not reduce NET mRNA in locus coeruleus $(p>0.05$; Table 1$)$.

\section{Effects of Reboxetine}

The relationship between the effect of chronic reboxetine treatment on NET expression and its effect on behavior in the forced-swim test was examined. Treatment of rats with $20 \mathrm{mg} / \mathrm{kg}$ per day reboxetine for 6 weeks, with a 2-day washout, reduced NET expression, as indicated by a reduction of the specific binding of ${ }^{3} \mathrm{H}$-nisoxetine to the NET in preparations of cerebral cortex $\left(\mathrm{F}_{(2,12)}=23.00\right.$, $p<0.0001$; Figure 2a) and hippocampus $\left(\mathrm{F}_{(2,12)}=3.78\right.$, $p<0.05$; Figure 2a); however, treatment for 2 weeks did not alter NET expression significantly. By contrast, SERT expression (ie ${ }^{3} \mathrm{H}$-citalopram binding) was not altered by reboxetine treatment, either in preparations of cerebral cortex $\left(\mathrm{F}_{(2,14)}=1.67, p>0.05\right.$; Figure $\left.2 \mathrm{~b}\right)$ or hippocampus $\left(\mathrm{F}_{(2,16)}=0.68, p>0.05\right.$; Figure $\left.2 \mathrm{~b}\right)$.

Downregulation of the NET by 6-week chronic reboxetine treatment also was demonstrated using SDS-PAGE/immunoblotting of preparations of cerebral cortex $\left(\mathrm{F}_{(2,13)}=5.99\right.$, $p<0.05$; Figure 2c) and hippocampus $\left(\mathrm{F}_{(2,16)}=2.94\right.$, $p<0.05$; Figure 2c). By contrast, this treatment did not alter SERT expression, measured by immunoblotting, in either cerebral cortex or hippocampus (Figure 2d). Interestingly, repeated treatment with $15 \mathrm{mg} / \mathrm{kg}$ desipramine for 14 days reduced SERT expression in cerebral cortex and hippocampus as evidenced using ${ }^{3} \mathrm{H}$-citalopram binding (40-50\% reduction; data not shown).

In parallel with the downregulation of the NET, chronic treatment with reboxetine for 6 weeks also produced a reduction in the duration of immobility in the forced-swim test, indicative of an antidepressant-like effect $\left(\mathrm{F}_{(2,15)}=34.01, p<0.001\right.$; Figure 2e). Although the 2-week reboxetine treatment did not reduce NET expression in cerebral cortex or hippocampus, an antidepressant-like effect still was observed in the forced-swim test following this treatment (Figure 2e).

To determine whether the downregulation of NET resulted from a change in NET gene transcription, NET mRNA expression in the locus coeruleus and SERT mRNA expression in the dorsal and medial raphe nucleus were measured using quantitative RT-PCR. The normalized, relative NET mRNA expression in the locus coeruleus was elevated, about threefold, 2 days after discontinuation of chronic reboxetine treatment $(p<0.001$; Table 1). The normalized, relative SERT mRNA expression in the dorsal and medial raphe nucleus was increased about 2.5 -fold $(p<0.01$; Table 1$)$. 
Table I Effects of Chronic Antidepressant Treatment on NET mRNA Expression in the Locus Coeruleus and SERT mRNA Expression in the Raphe Nucleus

\begin{tabular}{|c|c|c|}
\hline $\begin{array}{l}\text { Antidepressant } \\
\text { (mg/kg per day) }\end{array}$ & $\begin{array}{l}\text { Normalized NET } \\
\text { mRNA level in locus } \\
\text { coeruleus }\end{array}$ & $\begin{array}{l}\text { Normalized SERT } \\
\text { mRNA level in raphe } \\
\text { nuclei }\end{array}$ \\
\hline \multicolumn{3}{|l|}{ Protriptyline } \\
\hline Control & $1.4 \pm 0.3$ & ND \\
\hline 20 & $1.8 \pm 0.3$ & ND \\
\hline 10 & $1.7 \pm 0.2$ & ND \\
\hline \multicolumn{3}{|l|}{ Desipramine } \\
\hline Control & $1.6 \pm 0.5$ & ND \\
\hline 15 & $2.4 \pm 0.4$ & ND \\
\hline \multicolumn{3}{|l|}{ Reboxetine } \\
\hline Control & $1.1 \pm 0.1$ & $1.0 \pm 0.1$ \\
\hline 20 & $3.1 \pm 0.7 * * * *$ & $2.6 \pm 0.7 * * *$ \\
\hline \multicolumn{3}{|l|}{ Sertraline } \\
\hline Control & ND & $1.2 \pm 0.3$ \\
\hline PCPA & ND & $0.2 \pm 0.1 * * * *$ \\
\hline 7.5 & ND & $1.5 \pm 0.3$ \\
\hline $\mathrm{PCPA}+7.5$ & ND & $0.4 \pm 0.2 * * * *$ \\
\hline
\end{tabular}

Abbreviations: NET, norepinephrine transporter; ND, not determined; PCPA, treatment with $p$-chlorophenylalanine to inhibit serotonergic neurotransmission during the 3 days before the forced-swim test; SERT, serotonin transporter.

Rats were treated chronically for 2 weeks with antidepressants through osmotic pumps. NET and SERT mRNA were determined by real-time PCR 2 days after discontinuation of chronic treatment ( I day post-treatment for $10 \mathrm{mg} / \mathrm{kg}$ protriptyline). Values shown are ratios relative to I8S rRNA (mean \pm SEM; $n=5$ /group). $* * * 0<0.01, * * * * 0<0.001$

\section{Effects of Sertraline}

Given the apparent relationship between the downregulation of the NET by chronic treatment with NRIs and persistent antidepressant-like effects in the forced-swim test, it was of interest to also examine the relationship between changes in SRI-induced SERT expression and behavior. Rats were treated chronically with $7.5 \mathrm{mg} / \mathrm{kg}$ per day sertraline for 14 days and subjected to the forced-swim test 2 days after the end of sertraline treatment (ie removal of the osmotic pumps), and SERT expression was determined in several brain regions using ${ }^{3} \mathrm{H}$-citalopram binding and western blotting. Further, to determine whether enhanced serotonergic neurotransmission was necessary for the persistent antidepressant effect in the forcedswim test, a serotonin depletion approach was utilized, similar to that used to assess the role of serotonergic neurotransmission in the clinical actions of sertraline (Miller et al, 1996a). Rats were treated with PCPA, an inhibitor of tryptophan hydroxylase, the rate-limiting enzyme for serotonin biosynthesis. PCPA $(300 \mathrm{mg} / \mathrm{kg}$, i.p.) was administrated twice daily for 3 consecutive days with the last dose given $18 \mathrm{~h}$ before behavioral test (O'Leary et al, 2007) to rats that had been treated chronically with vehicle or sertraline.
A significant reduction of SERT binding sites, measured using ${ }^{3} \mathrm{H}$-citalopram, was evident 2 days after the discontinuation of chronic sertraline treatment in the cerebral cortex $\left(\mathrm{F}_{(3,18)}=8.17, p<0.01\right.$; Figure $\left.3 \mathrm{a}\right)$ and hippocampus $\left(\mathrm{F}_{(3,18)}=10.06, p<0.001\right.$; Figure $\left.3 \mathrm{a}\right)$. By contrast, NET expression (ie ${ }^{3} \mathrm{H}$-nisoxetine binding) was not altered by sertraline treatment, either in preparations of cerebral cortex or hippocampus (Figure 3b).

The downregulation of the SERT also was demonstrated using SDS-PAGE/immunoblotting of preparations of cerebral cortex $\left(\mathrm{F}_{(3,16)}=6.94, p<0.01\right.$; Figure $\left.3 \mathrm{c}\right)$ and hippocampus $\left(\mathrm{F}_{(3,16)}=14.37, p<0.001\right.$; Figure $\left.3 \mathrm{c}\right)$. By contrast, this treatment did not alter NET expression, measured by immunoblotting, in either cerebral cortex or hippocampus (Figure 3d).

In parallel with the downregulation of the SERT, chronic sertraline treatment also produced an antidepressant-like effect in the forced-swim test, demonstrated by a reduction of immobility time $\left(\mathrm{F}_{(3,19)}=19.57, p<0.001\right.$; Figure $\left.3 \mathrm{e}\right)$. Three-day, twice daily treatment with $300 \mathrm{mg} / \mathrm{kg}$ per day PCPA, to reduce serotonin neurotransmission, reversed the behavioral actions of chronic sertraline treatment, demonstrated by the increased immobility time (Figure 3e); PCPA, when administered alone, did not affect behavior in the forced-swim test (Figure 3e), nor did it alter SERT expression (Figure $3 \mathrm{c}$ ).

Overall, there was a significant effect of sertraline/PCPA administration on normalized, relative SERT mRNA expression in the dorsal and median raphe nucleus $\left(\mathrm{F}_{(3,18)}=28.5\right.$, $p<0.001$; Table 1). Post hoc tests revealed that although chronic sertraline treatment did not change the SERT mRNA expression, a significant decrease in SERT mRNA expression was found in the groups treated with PCPA alone or in combination with chronic sertraline (Table 1).

\section{Effects of Venlafaxine}

Given that venlafaxine inhibits both the NET and SERT, ie it is an SNRI, it was of interest to explore the relationship between venlafaxine-induced changes in NET and SERT expression and behavior. Rats were treated chronically with $70 \mathrm{mg} / \mathrm{kg}$ per day venlafaxine for 14 days and subjected to the forced-swim test 2 days after the end of venlafaxine treatment. NET and SERT binding sites were determined in several brain regions using ${ }^{3} \mathrm{H}$-nisoxetine and ${ }^{3} \mathrm{H}$ citalopram binding. NET and SERT protein expression was determined by western blotting. Treatment of $70 \mathrm{mg} / \mathrm{kg}$ per day venlafaxine did not alter NET (Figure 4a) or SERT binding sites (Figure $4 \mathrm{~b}$ ) in cerebral cortex and hippocampus. Consistently, NET and SERT protein expression in cerebral cortex and hippocampus was not changed after chronic venlafaxine treatment (Figure $4 \mathrm{c}$ and $\mathrm{d}$ ). However, in spite of the lack of any change in NET or SERT expression, an antidepressant-like effect in the forced-swim test was observed 2 days after the end of the chronic venlafaxine treatment period $(p<0.001$; Figure 4e).

\section{Effects of Phenelzine}

To determine whether enhanced monoaminergic neurotransmission, independent of NET or SERT inhibition, 


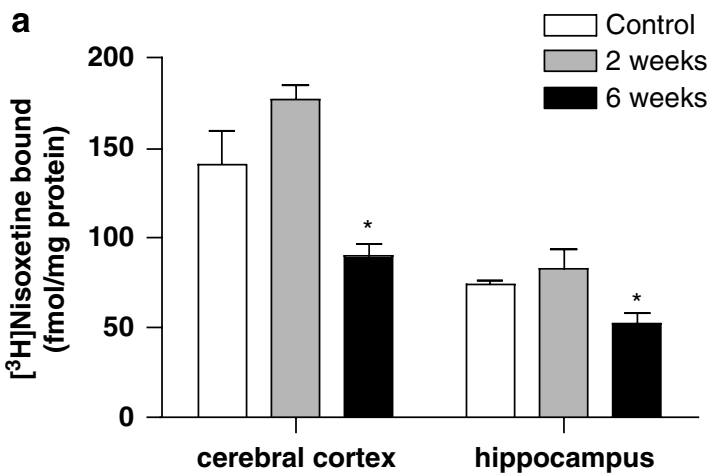

c

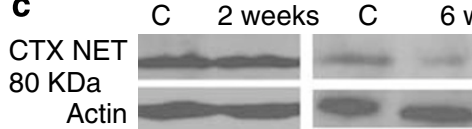

Actin

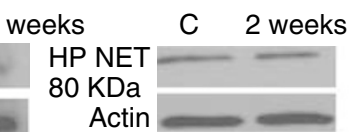

Control

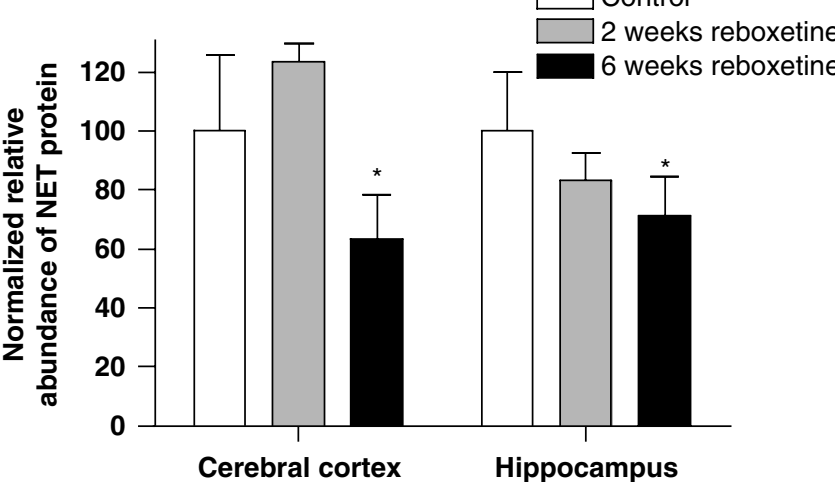

b

Control

2 weeks reboxetine

6 weeks reboxetine

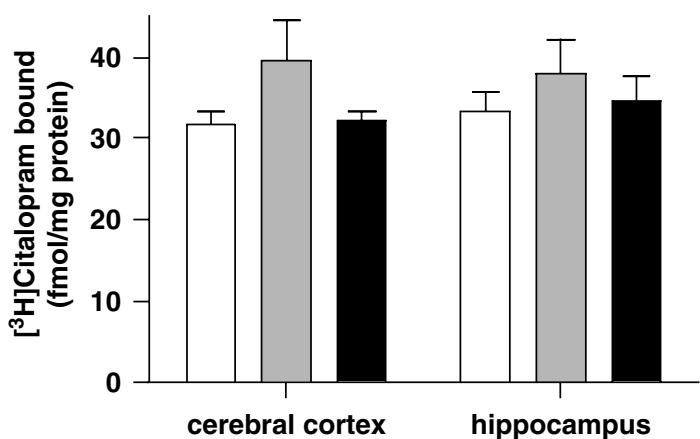

C 6 weeks

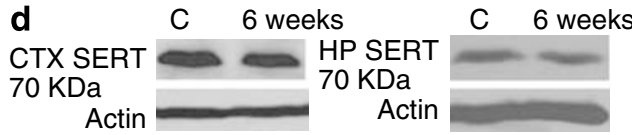

Actin

$\square$ Control
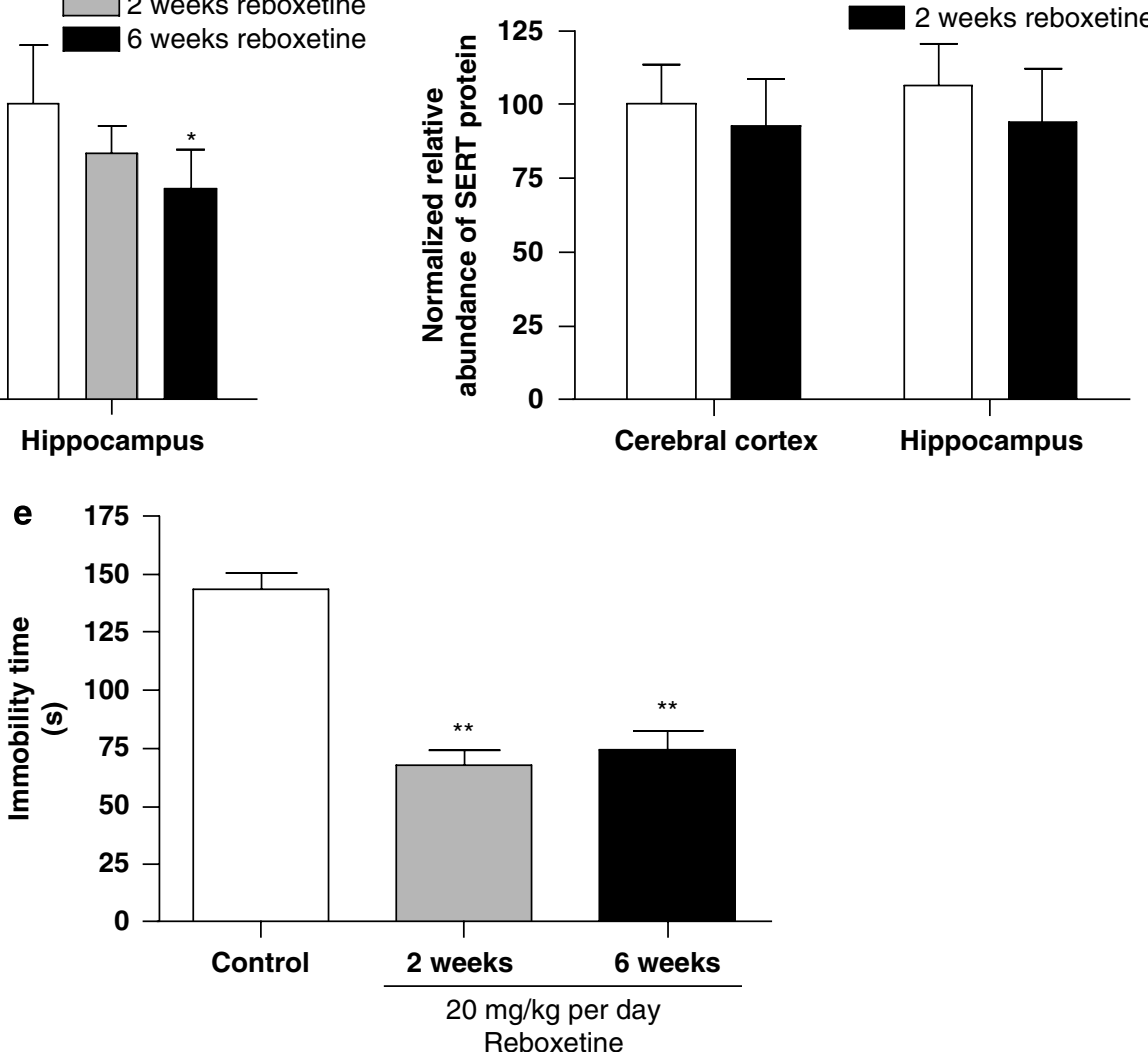

Figure 2 Chronic treatment with reboxetine (20 mg/kg per day) for 6 weeks, but not 2 weeks, reduced norepinephrine transporter (NET) binding sites in both cerebral cortex and hippocampus, but not serotonin transporter (SERT) binding sites (a, b). The NET protein expression in the cerebral cortex and hippocampus determined by SDS-PAGE/immunoblotting with antisera against the NET was significantly reduced after 6-week treatment, but not after 2-week treatment (c). Persistent antidepressant-like effects in the forced-swim test were evident 2 days after the end of both the 2-and 6-week chronic treatment regimens (d). Data shown are means \pm SEM of 5-6 rats per group. $* p<0.05, * * 2<0.01$ vs control.

was sufficient to alter expression of the transporters, the effects of the monoamine oxidase inhibitor phenelzine were determined. Rats were treated with $10 \mathrm{mg} / \mathrm{kg}$ per day phenelzine (i.p.) for 14 days and subjected to the forcedswim test 2 days after the end of the treatment period. NET and SERT expression was then assessed in cerebral cortex and hippocampus.
Phenelzine treatment did not alter NET or SERT expression in cerebral cortex or hippocampus, measured by ${ }^{3} \mathrm{H}$-nisoxetine and ${ }^{3} \mathrm{H}$-citalopram binding (Figure $5 \mathrm{a}$ and b) and SDS-PAGE/immunoblotting (Figure $5 \mathrm{c}$ and d). However, a significant decrease in immobility time in the forced-swim test was observed 2 days following the end of chronic phenelzine treatment ( $p<0.001$; Figure 5e). 

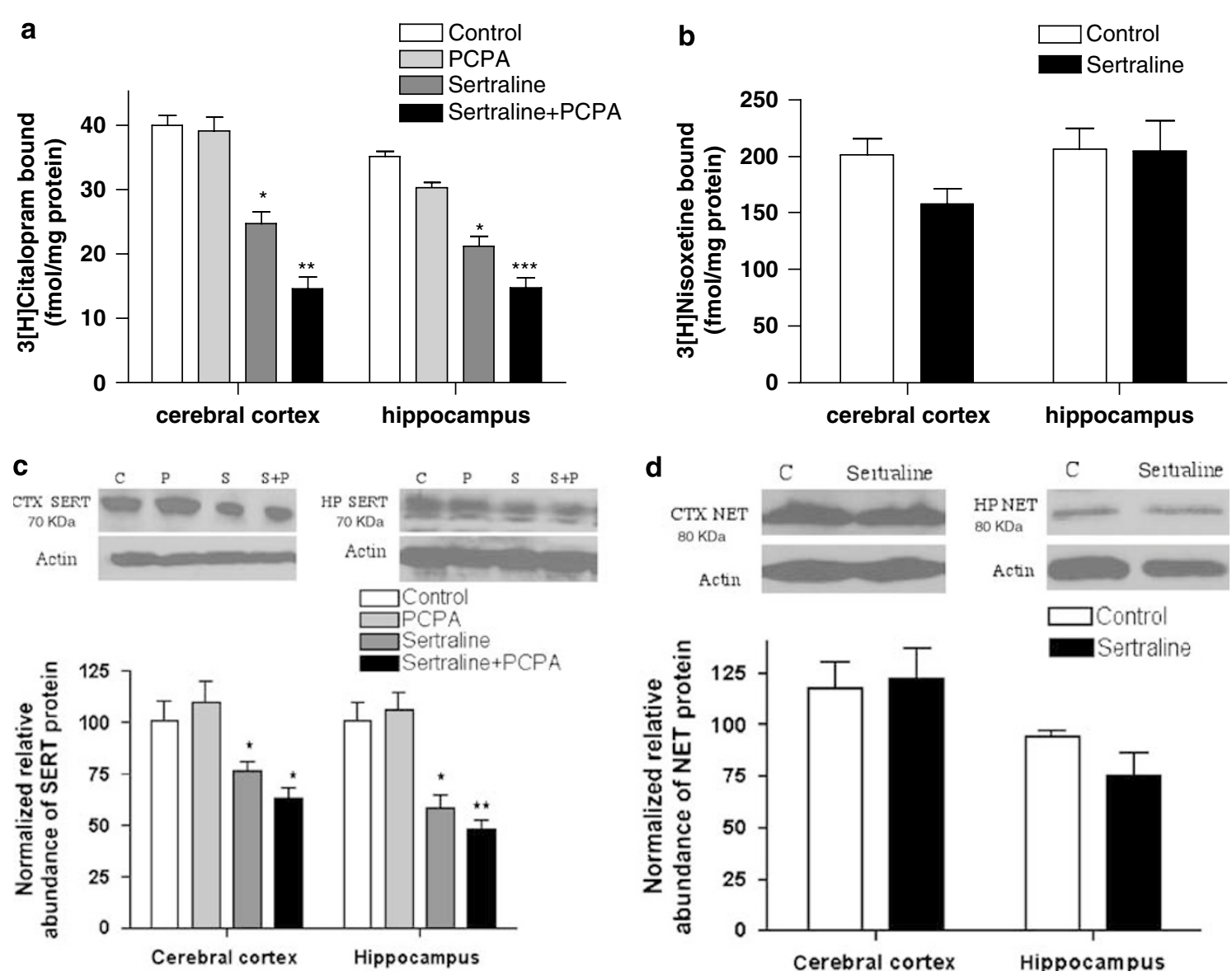

d
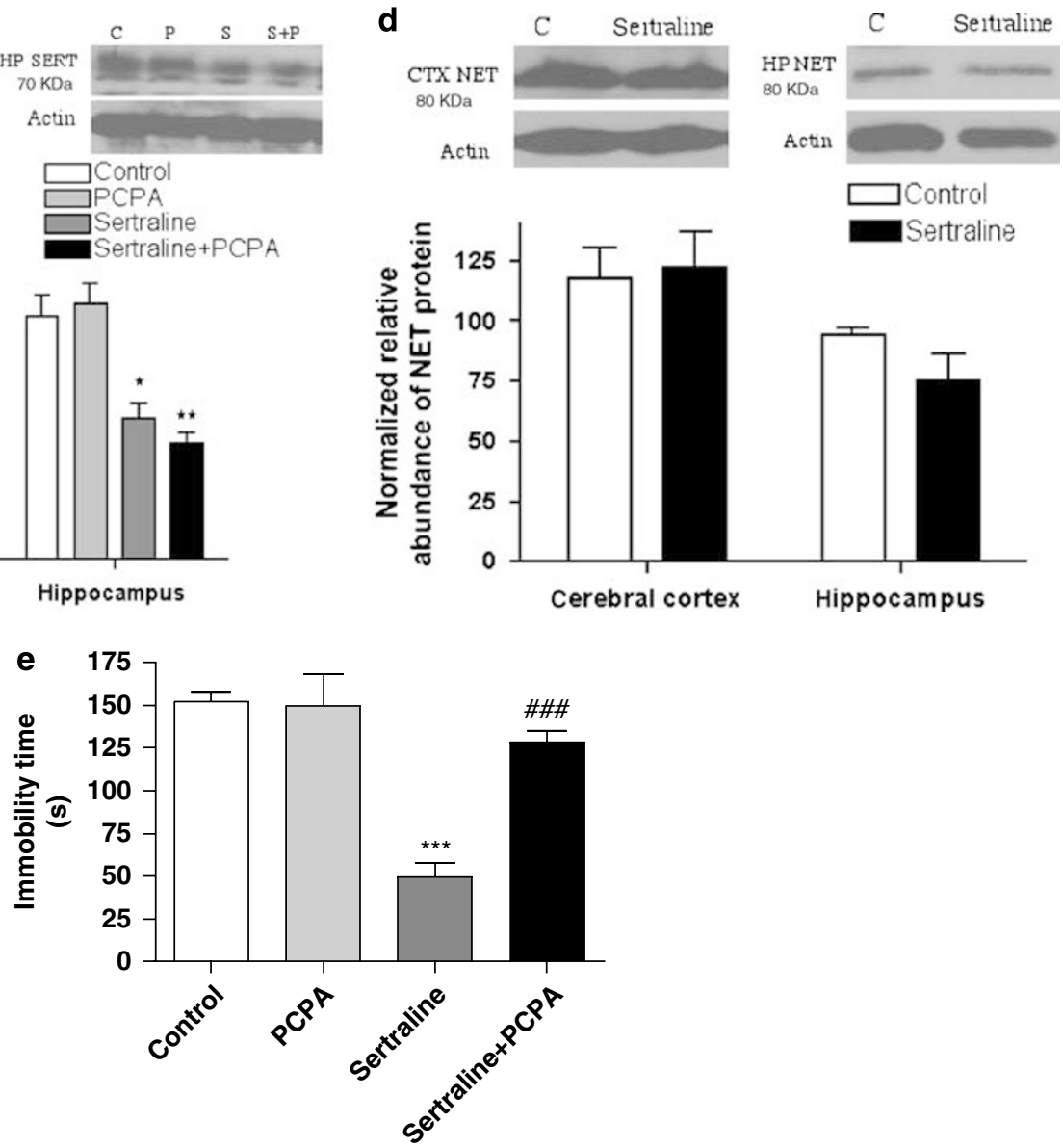

Figure 3 Chronic treatment with sertraline $(7.5 \mathrm{mg} / \mathrm{kg}$ per day) for 2 weeks reduced serotonin transporter (SERT) expression in the cerebral cortex and hippocampus, measured by ${ }^{3} \mathrm{H}$-citalopram binding (a) and SDS-PAGE/immunoblotting (c), but did not affect norepinephrine transporter (NET) expression in the cerebral cortex and hippocampus, determined by ${ }^{3} \mathrm{H}$-nisoxetine binding (b) and SDS-PAGE/immunoblotting (d). Sertraline treatment also produced a persistent antidepressant-like effect on forced-swim behavior (e). To examine whether enhanced serotonergic neurotransmission was necessary for the persistent antidepressant-like effect in the forced-swim test, p-chlorophenylalanine (PCPA), an inhibitor of tryptophan hydroxylase, was administered $(300 \mathrm{mg} / \mathrm{kg}$, i.p.) twice daily for 3 consecutive days with the last dose given $18 \mathrm{~h}$ before the forced-swim test. PCPA reversed the sertraline-induced antidepressant-like effect in the forced-swim test, but did not affect behavior on its own (e); it did not alter the effect of sertraline on SERT expression (a, c). Data shown are means \pm SEM of 5-8 rats per group. ${ }^{*} p<0.05$, $* * * 0.01, * * * p<0.00$ I vs control, \#\#\# ${ }^{*}<0.00$ I vs sertraline alone.

\section{DISCUSSION}

In a previous study, a relationship between desipramineinduced downregulation of the NET and antidepressant effects on behavior was observed (Zhao et al, 2008). The downregulation of the NET is associated with antidepressant effects on behavior, even when there is no detectable drug present to inhibit NE reuptake. Desipramine-induced downregulation of the NET and the development of persistent antidepressant-like effects on behavior develop gradually with repeated treatment, consistent with the development of the clinical response to antidepressants (Frazer and Benmansour, 2002; Katz et al, 1996, 2004; Gelenberg and Chesen, 2000). This suggests that neural adaptation resulting in enhanced monoaminergic neurotransmission may be a key mechanism mediating anti- 
a

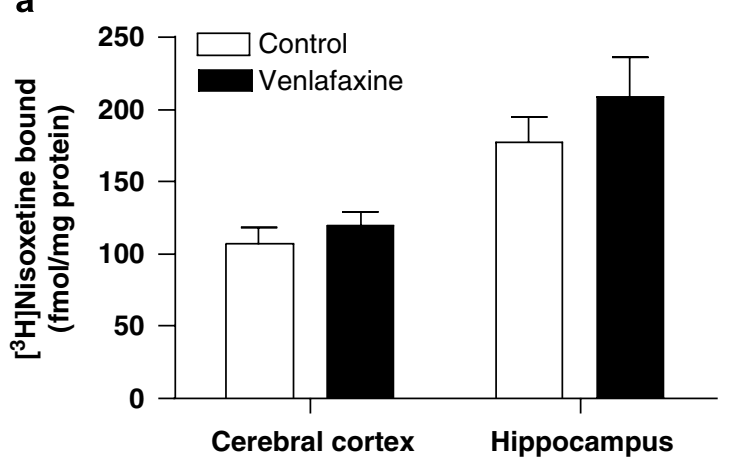

C

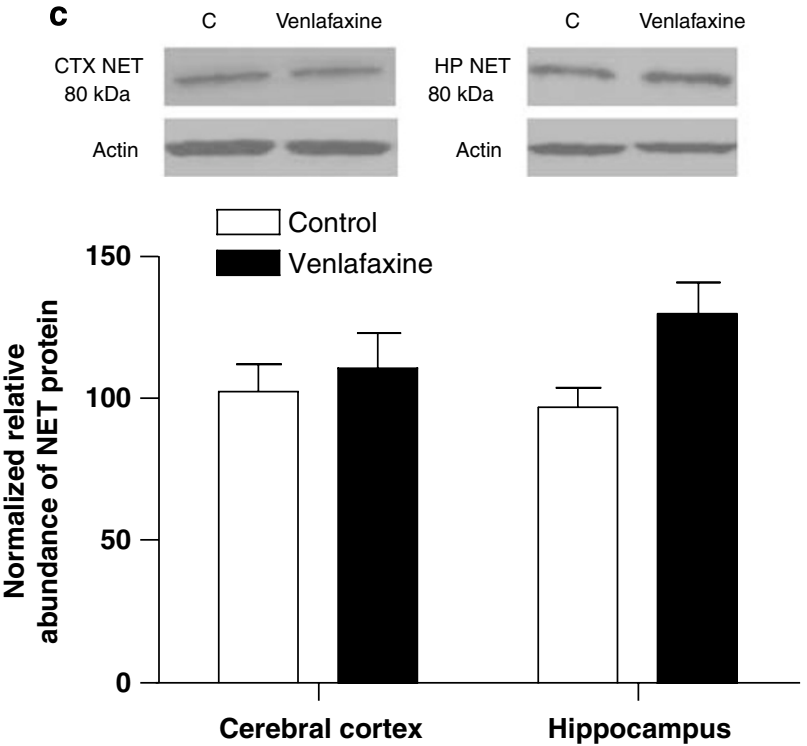

b
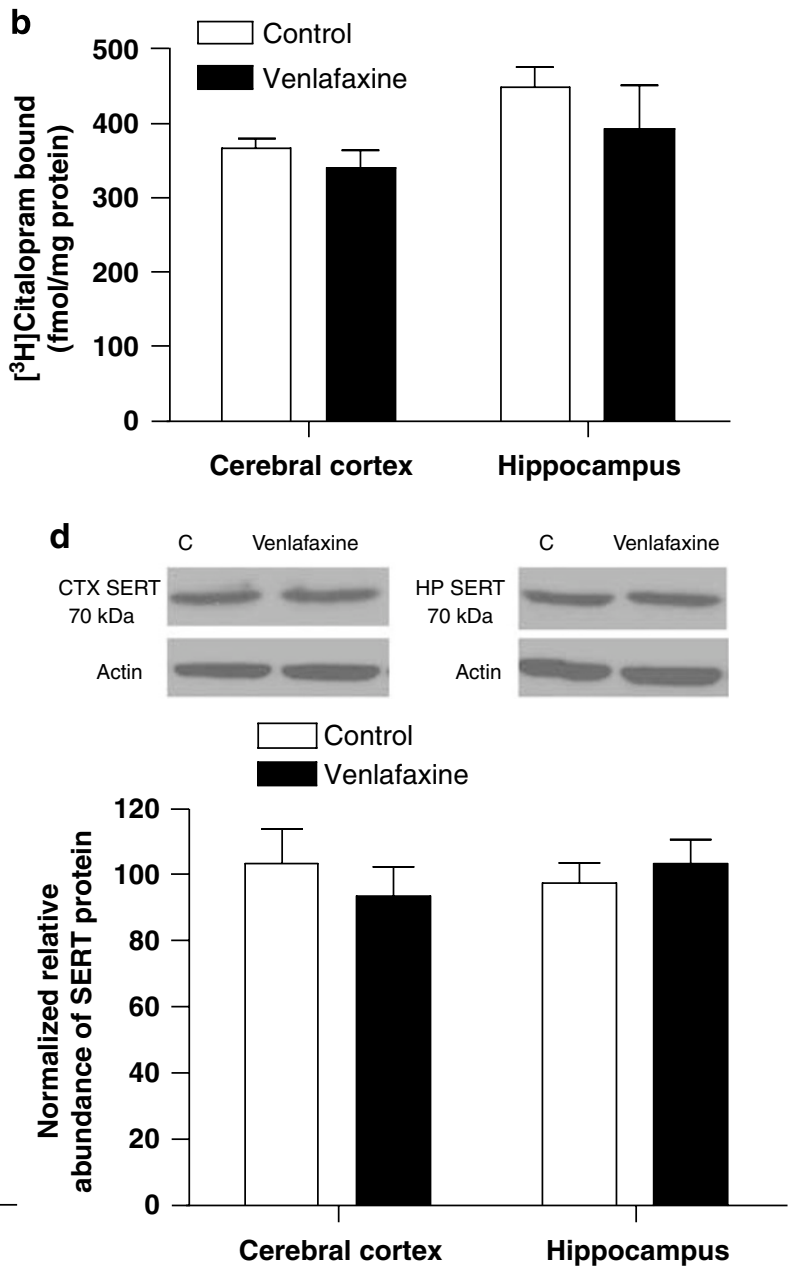

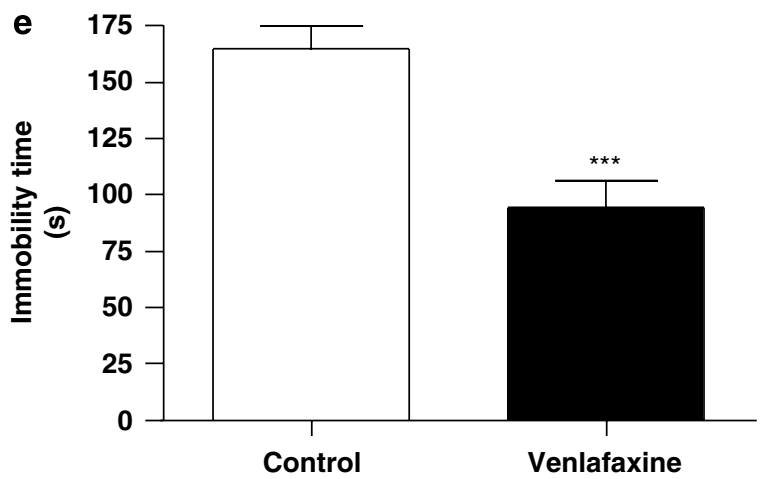

Figure 4 Chronic treatment with venlafaxine $(70 \mathrm{mg} / \mathrm{kg}$ per day) for 2 weeks did not affect norepinephrine transporter (NET) or serotonin transporter (SERT) expression in cerebral cortex or hippocampus, determined by radioligand binding (a, b) and SDS-PAGE/immunoblotting binding (c, d). However, a persistent antidepressant-like effect on forced-swim behavior was evident 2 days after the end of the chronic treatment period (e). Data shown are means \pm SEM of $5-6$ rats per group. $* * * * p<0.00$ I vs control.

depressant actions. Consistent with this, it was found that inhibition of catecholamine synthesis with AMPT reverses the persistent antidepressant-like effect of desipramine in the forced-swim test (Zhao et al, 2008); similar effects have been observed in depressed patients treated with desipramine (Charney, 1998; Miller et al, 1996b). The results of the present study demonstrated that NET downregulation appears to be important for the actions of protriptyline and reboxetine, two other antidepressants that interact with the NET. Further, SERT downregulation contributes to the long-term behavioral effects of the SRI sertraline.

NET expression, measured by ${ }^{3} \mathrm{H}$-nisoxetine binding and SDS-PAGE/immunoblotting, was reduced after 14 days of treatment with protriptyline or 42 days of treatment of reboxetine, similar to the effect observed after repeated treatment with desipramine (Zhao et al, 2008). $\beta-1$ adrenergic receptor density also is reduced after chronic desipramine, protriptyline, or reboxetine treatment 

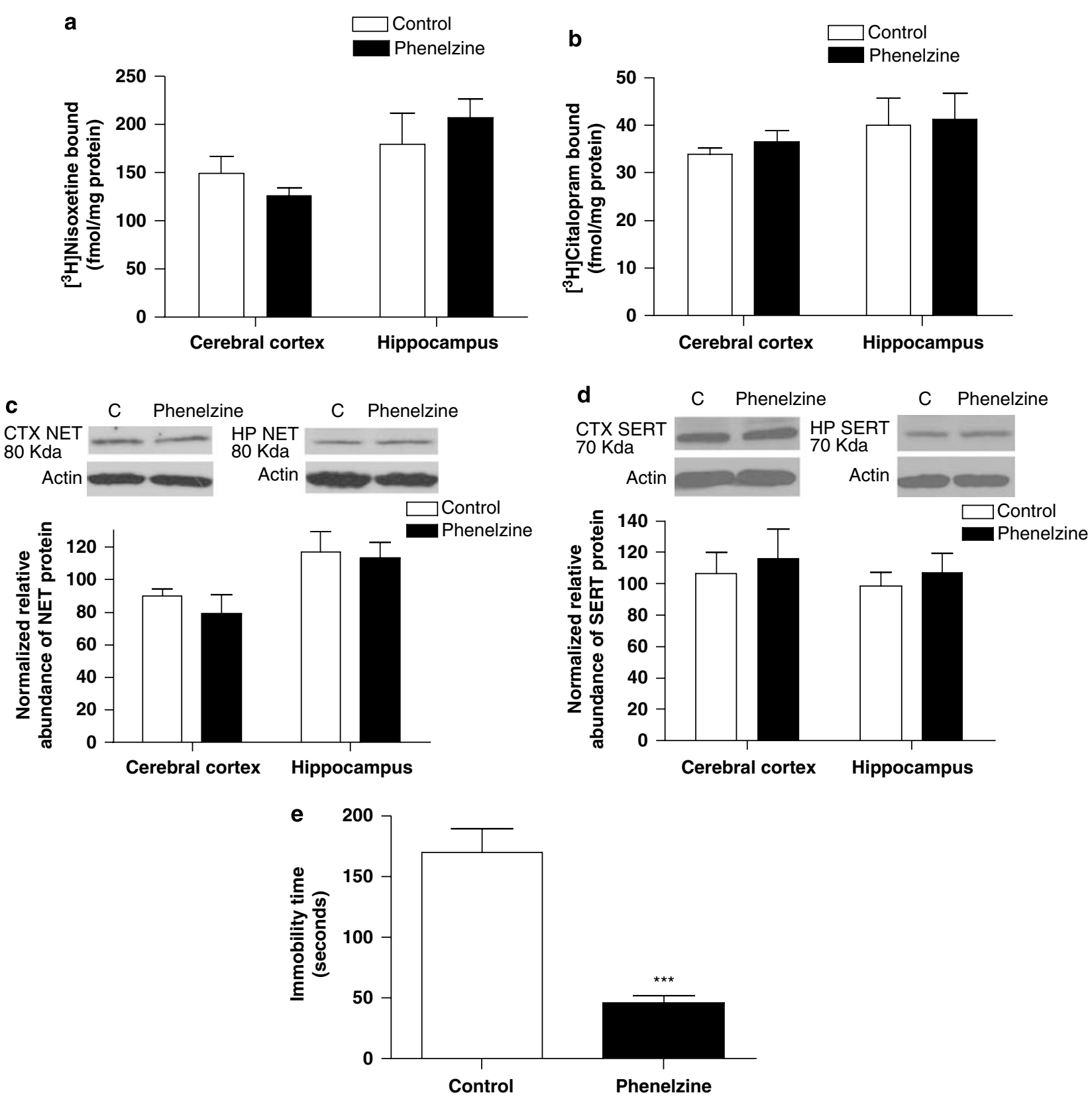

Figure 5 Chronic treatment with phenelzine $(10 \mathrm{mg} / \mathrm{kg}$ per day) for 2 weeks did not affect norepinephrine transporter (NET) or serotonin transporter (SERT) expression in cerebral cortex or hippocampus, determined by radioligand binding (a, b) and SDS-PAGE/immunoblotting binding (c, d). However, a persistent antidepressant-like effect on forced-swim behavior was evident 2 days after the end of the chronic treatment period (e). Data shown are means \pm SEM of $5-6$ rats per group. $* * * * p<0.00$ I vs control.

(Ordway et al, 1991; Gould et al, 2003). This suggests that NET downregulation results in increased noradrenergic neurotransmission; this has been verified experimentally for desipramine and reboxetine treatment using in vivo microdialysis (Page and Lucki, 2002; Lapiz et al, 2007; Zhao et al, 2008).

NET downregulation in response to NRI treatment, in addition to being observed in vivo (Zhu et al, 2002; Weinshenker et al, 2002; Zhao et al, 2008), also has been shown in vitro in cell lines expressing the NET. NET expression in SK-N-BE(2)M17 cells is decreased following 3-14 days of exposure to desipramine (Zhu et al, 1998). Chronic desipramine-induced NET downregulation also is observed with PC12 and human neuroblastoma cells (Zhu and Ordway, 1997; Zhu et al, 2005), as well as HEK293 cells transfected with the NET (Zhu et al, 1998). Because these cells lack synaptic innervation, these findings suggest that desipramine-induced NET regulation is, at least in part, a direct effect of occupation of the NET, and not secondary to an increase in the extracellular concentration of NE. Consistent with this interpretation, it was found that chronic treatment with the monoamine oxidase inhibitor phenelzine, which increases noradrenergic neurotransmission, does not downregulate the NET. However, it did produce antidepressant-like effects in the forcedswim test. 
In the present study, it was found that repeated treatment with the SRI sertraline reduced SERT expression, measured using ${ }^{3} \mathrm{H}$-citalopram binding and SDS-PAGE/immunoblotting. Previously, it has been found that SERT density in the CA3 region of the hippocampus, assessed by quantitative autoradiography with ${ }^{3} \mathrm{H}$-cyanoimipramine, is decreased by $80-90 \%$ by chronic sertraline or paroxetine treatment (Benmansour et al, 1999). After 15 days of sertraline treatment, SERT binding sites are reduced by $80 \%$, accompanied by a marked reduction of serotonin clearance (Benmansour et al, 2002). SERT density in the dentate gyrus, lateral nucleus of the amygdala, and dorsal raphe, measured by ${ }^{3} \mathrm{H}$-cyanoimipramine binding, is significantly reduced after chronic paroxetine treatment (Gould et al, 2003). Similarly, using ${ }^{3} \mathrm{H}$-citalopram homogenate binding, SERT binding sites in the rat prefrontal cortex are reduced after chronic paroxetine or sertraline treatment (Gould et al, 2006). SERT expression in mouse brain regions is reduced after chronic paroxetine treatment; this effect persists for $120 \mathrm{~h}$ after 21 days of treatment (Hirano et al, 2005b). In humans, it has been reported that treatment with $40 \mathrm{mg} /$ day citalopram for 8 days reduces SERT binding sites in the diencephalon and brainstem (Kugaya et al, 2003). To date, it had not been determined whether persistent downregulation of the SERT resulted in the antidepressant effects on behavior. In the present study, it was found that 2 days following discontinuation of sertraline treatment, when SERT expression was reduced in cerebral cortex and hippocampus, a persistent antidepressant-like effect in the forced-swim test was observed.

In HEK cells expressing the SERT, its binding sites are reduced after a 3-day incubation with $500 \mathrm{nM}$ citalopram; this is accompanied by decreased maximal transporter activity $\left(V_{\max }\right)$ and an unchanged $K_{\mathrm{m}}$ value (Horschitz et al, 2001). In vitro, downregulation of SERT is associated with protein kinase $\mathrm{C}(\mathrm{PKC})$ activation-induced phosphorylation of specific amino-acid residues, which triggers translocation of SERT from membrane to cytoplasm (Jayanthi et al, 2004; Sung et al, 2005; Sung and Blakely, 2007; Amano et al, 2006). Qian et al (1997) and Lau et al (2008) also have shown that stimulation of PKC causes internalization of cell-surface SERT protein. Given the present data that antidepressant-induced reductions in SERT and NET expression are not due to reduced transcription, it is possible that these mechanisms involving transporter internalization may be important in vivo.

Although treatment with the NRI reboxetine reduced NET expression without altering the SERT, consistent with its reported selectivity (Wong et al, 2000; Millan et al, 2001; Versiani et al, 1999), desipramine treatment reduced expression of both the NET and the SERT. This may result from a lack of selectivity for desipramine for the NET at the dose tested (Iversen, 2006) or may be due to the effects of desipramine's primary, active metabolite desmethyldesipramine, which reaches concentrations similar to the parent compound (Kozisek et al, 2007). In preparations of rat brain, desmethyldesipramine exhibits 12-fold greater affinity for the SERT compared with the NET; desmethyldesipramine's affinity for the SERT is similar to desipramine's for the NET (Deupree et al, 2007). Thus, immediately after desipramine administration, when the desipramine concentration is much higher than that of desmethyldesipra- mine, the pharmacological effect of desipramine might be associated primarily with the NET, while later as the concentration of the longer-lived metabolite desmethyldesipramine increases, both SERT and NET may be involved.

Among the adaptive changes that may underlie the longterm effects of antidepressant treatment, NET and SERT regulation fit with the clinical data to a considerable degree. From a functional perspective, the direction of the longterm change in transporter expression following antidepressant treatment is the same as that seen with acute treatment with an antidepressant. In both cases, there is a reduction in transporter function and enhanced monoaminergic neurotransmission. By contrast, changes in monoaminergic receptor expression often are homeostatic, ie in opposition to the effect of acute antidepressant treatment (Ordway et al, 1991). Preclinically, AMPT partially prevents the acute desipramine response, whereas a combination of AMPT and reserpine completely prevents the behavioral effects of acute desipramine (O'Leary et al, 2007); this suggests that disruption of both catecholamine synthesis and vesicular storage and release are required to completely block desipramine's effects. PCPA, a tryptophan hydroxylase inhibitor (Koe and Weissman, 1966), completely reverses the antidepressant-like effect produced by acute treatment with the SRIs fluoxetine and citalopram (Page et al, 1999; O'Leary et al, 2007). In normal, euthymic subjects, it has been shown that reducing catecholaminergic activity with AMPT or serotonergic activity with tryptophan depletion does not induce symptoms of depression, indicating that monoamine deficiency itself is insufficient to cause depression (Miller et al, 1996a). However, catecholamine depletion by AMPT results in the return of symptoms of depression in depressed patients treated chronically with NRIs such as desipramine, but not SRIs (Miller et al, 1996a,b; Bremner et al, 2003). By contrast, inhibition of serotonin synthesis with PCPA or a tryptophan-free amino-acid drink reverses symptom remission caused by SRIs, but not NRIs (Miller et al, 1996a; Salomon et al, 1993).

Consistent with these clinical data, it has been found in an earlier study that inhibition of catecholamine synthesis with AMPT reverses the persistent antidepressant-like effect of desipramine in the forced-swim test (Zhao et al, 2008); changes in both noradrenergic and dopaminergic neurotransmission may contribute to this effect of AMPT (O'Donnell and Seiden, 1984). A role for noradrenergic neurotransmission is suggested by the finding that NEdeficient mice fail to respond to the behavioral effects of the NRI desipramine. Restoration of noradrenergic function by 1-threo-3,4-dihydroxyphenylserine reinstates the behavioral effects of desipramine in these mice (Cryan et al, 2004). In the present study, it was found that inhibition of serotonin synthesis with PCPA reversed the persistent antidepressantlike effect of sertraline in the forced-swim test. Overall, the preclinical and clinical data suggest that enhanced monoaminergic neurotransmission is necessary, but not sufficient, for producing antidepressant effects, at least for those drugs that act through inhibition of reuptake.

Whether the downregulation of the NET or SERT is mediated by altered gene transcription has been a point of investigation. Previous studies using HEK-293 and SK-NBE(2)M17 cells have shown that desipramine-induced 
reduction of NET expression primarily is because of translocation or increased degradation of the NET, but have not ruled out altered transcription (Zhu et al, 1998, 2002). However, in vivo, it is found that NET mRNA expression in the locus coeruleus is elevated after chronic desipramine treatment (Szot et al, 1993). Further, it is found that the SERT mRNA expression in the raphe nucleus is unchanged following chronic treatment with SRIs (Benmansour et al, 1999; Abumaria et al, 2007). Lopez et al (1994) found that the SERT mRNA level is increased after chronic antidepressant treatment, whereas Lesch et al (1993) reported a decreased SERT mRNA level. In vitro, the expression of NET mRNA in human enterocyte-like cell line Caco-2 (Iceta et al, 2007) and SERT-expressing HEK293 cells (Lau et al, 2008) is unaltered after chronic SRIs treatment. In the present study, it was found that NET mRNA expression in the rat locus coeruleus was unchanged after chronic desipramine or protriptyline treatment, whereas it was elevated threefold after the 6-week reboxetine treatment regimen. Given that the change in NET protein expression produced by these drugs is reduced, ie in the opposite direction, it is unlikely that chronic antidepressant-induced downregulation of the NET is regulated at the transcriptional level. In fact, exposure to reboxetine for 6 weeks might trigger a compensatory increase in transcription. Changes in SERT mRNA also do not appear to account for sertraline-induced changes in SERT protein expression. However, although sertraline treatment alone did not alter SERT mRNA, PCPA alone or in combination with sertraline reduced it. Interestingly, SERT mRNA expression in the raphe nucleus was increased after the 6week reboxetine treatment; the mechanisms mediating this effect and its functional significance are unclear.

It seems that downregulation of NET or SERT is not the only mechanism mediating persistent antidepressant-like behavioral effects. Treatment of rats with $20 \mathrm{mg} / \mathrm{kg}$ per day reboxetine for 2 weeks did not reduce the NET expression but did produce an antidepressant-like effect in the forcedswim test 2 days after the end of the treatment period. Further, 2-week treatment with $70 \mathrm{mg} / \mathrm{kg}$ per day venlafaxine treatment failed to decrease the NET or SERT expression but still produced a persistent antidepressant-like effect in the forced-swim test. It also was reported that NET and SERT binding sites, measured using quantitative autoradiography with ${ }^{3} \mathrm{H}$-citalopram, are not reduced in the CA3 region of hippocampus after treatment for 21 days with 15 or $70 \mathrm{mg} / \mathrm{kg}$ per day venlafaxine (Gould et al, 2006). Similarly, chronic treatment with amitriptyline, a tricyclic antidepressant that inhibits both the NET and SERT, also fails to reduce SERT and NET binding sites (Owens et al, 1997). The inability of venlafaxine to downregulate the NET or SERT following chronic treatment is not because of a lack of efficacy, as treatment with $70 \mathrm{mg} / \mathrm{kg}$ per day causes a downregulation of $\beta$-1 adrenergic receptors in the same rats in which no downregulation of the transporters is observed (Gould et al, 2006). Also, chronic venlafaxine produces a dose-dependent attenuation of the hypothermic response of rats to acute treatment with 8-OH-DPAT, a serotonin-1A receptor agonist, similar to the effects produced by sertraline and citalopram (Hensler, 2003; Rossi et al, 2005). The reason why chronic reboxetine and venlafaxine failed to downregulate NET or SERT but still showed antidepressant- like behavioral effects is not known. It is possible that differential stimulation of heteroreceptors (Chiang and Aston-Jones, 1993; Mongeau et al, 1993), distinct interactions with P450 isoenzymes (Cadieux, 1999; Tanaka, 1998), different binding affinities for the transporters (Lenox and Frazer, 2002), and details regarding the nature and location of binding to the NET or SERT (Larsen et al, 2004; Schmid et al, 2001) may account for the observed differences among the effects of the antidepressants tested.

Overall, the present results demonstrate that reduced NET and SERT expression contributes to the development of antidepressant-like effects on behavior; this is evident for desipramine, protriptyline, and sertraline. However, this does not appear to be the only mechanism contributing to such effects, as some antidepressants, notably venlafaxine, produce persistent antidepressant-like effects on behavior without altering NET or SERT expression. Also, consistent with clinical data, it was found that the antidepressant-like effect that resulted from SERT downregulation depended on the enhanced serotonergic neurotransmission, as it was lost when serotonin synthesis was inhibited. A similar dependence of desipramine-induced NET downregulation on enhanced noradrenergic neurotransmission was demonstrated previously (Zhao et al, 2008). The present data provide support for the idea that the downregulation of NET and SERT may contribute to the long-term therapeutic effects of antidepressant drugs. The mechanism of NET and SERT regulation appears to be due more to altered internalization and degradation than altered transcription. Understanding the molecular mechanisms mediating NET and SERT regulation in vivo might suggest novel targets for therapeutic intervention in the treatment of depression.

\section{ACKNOWLEDGEMENTS}

This work was supported by research grants from the National Institute of Mental Health (MH051175 and MH040694).

\section{DISCLOSURE/CONFLICT OF INTEREST}

JM O'Donnell and HT Zhang have received research support from Memory Pharmaceuticals, Lundbeck Pharmaceuticals, NARSAD, and the National Institute of Mental Health. They declare no other conflicts of interest, financial or otherwise.

Z Zhao, E Bootzin, and MJ Millan declare no conflicts of interest, either financial or otherwise.

\section{REFERENCES}

Abumaria N, Rygula R, Hiemke C, Fuchs E, Havemann-Reinecke $\mathrm{U}$, Rüther $\mathrm{E}$ et al (2007). Effect of chronic citalopram on serotonin-related and stress-regulated genes in the dorsal raphe nucleus of the rat. Eur Neuropsychopharmacol 17: 417-429.

Amano T, Aoki S, Setsuie R, Sakurai M, Wada K, Noda M (2006). Identification of a novel regulatory mechanism for norepinephrine transporter activity by the IP3 receptor. Eur J Pharmacol 536: 62-68.

Artigas F, Celada P, Laruelle M, Adell A (2001). How does pindolol improve antidepressant action? Trends Pharmacol Sci 22 224-228. 
Benmansour S, Altamirano AV, Jones DJ, Sanchez TA, Gould GG, Pardon MC et al (2004). Regulation of the norepinephrine transporter by chronic administration of antidepressants. Biol Psychiatry 55: 313-316.

Benmansour S, Cecchi M, Morilak DA, Gerhardt GA, Javors MA, Gould GG et al (1999). Effects of chronic antidepressant treatments on serotonin transporter function, density, and mRNA level. J Neurosci 19: 10494-10501.

Benmansour S, Owens WA, Cecchi M, Morilak DA, Frazer A (2002). Serotonin clearance in vivo is altered to a greater extent by antidepressant-induced downregulation of the serotonin transporter than by acute blockade of this transporter. J Neurosci 22: 6766-6772.

Beyer CE, Boikess S, Luo B, Dawson LA (2002). Comparison of the effects of antidepressants on norepinephrine and serotonin concentrations in the rat frontal cortex: an in-vivo microdialysis study. J Psychopharmacol 16: 297-304.

Bremner JD, Vythilingam M, Ng CK, Vermetten E, Nazeer A, Oren DA et al (2003). Regional brain metabolic correlates of alpha-methylparatyrosine-induced depressive symptoms: implications for the neural circuitry of depression. JAMA 289: 3125-3134.

Bryan-Lluka LJ, Paczkowski FA, Bonisch H (2001). Effects of shortand long-term exposure to c-AMP and c-GMP on the noradrenaline transporter. Neuropharmacology 40: 607-617.

Cadieux RJ (1999). Antidepressant drug interactions in the elderly. Understanding the P-450 system is half the battle in reducing risks. Postgrad Med 106: 231-249.

Chamas F, Serova L, Sabban EL (1999). Tryptophan hydroxylase mRNA levels are elevated by repeated immobilization stress in rat raphe nuclei but not in pineal gland. Neurosci Lett 267: $157-160$.

Chamas FM, Underwood MD, Arango V, Serova L, Kassir SA, Mann JJ et al (2004). Immobilization stress elevates tryptophan hydroxylase mRNA and protein in the rat raphe nuclei. Biol Psychiatry 55: 278-283.

Charney DS (1998). Monoamine dysfunction and the pathophysiology and treatment of depression. J Clin Psychiatry 59: $11-14$.

Charney DS, Price LH, Heninger GR (1986). Desipramineyohimbine combination treatment for refractory depression. Arch Gen Psychiatry 45: 1155-1161.

Chiang C, Aston-Jones G (1993). A 5-hydroxytryptamine ${ }_{2}$ agonist augments gamma-aminobutyric acid and excitatory amino acid inputs to noradrenergic locus coeruleus neurons. Neuroscience 54: 409-420.

Crissman AM, O'Donnell JM (2002). Effects of antidepressants in rats trained to discriminate centrally administered isoproterenol. J Pharmacol Exp Ther 302: 606-611.

Cryan JF, Markou A, Lucki L (2002). Assessing antidepressant activity in rodents: recent developments and future needs. Trends Pharmacol Sci 23: 238-245.

Cryan JF, O'Leary OF, Jin SH, Friedland JC, Ouyang M, Hirsch BR et al (2004). Norepinephrine-deficient mice lack responses to antidepressant drugs, including selective serotonin reuptake inhibitors. Proc Natl Acad Sci 101: 8186-8191.

D'Amato RJ, Largent BL, Snowman AM, Snyder SH (1987). Selective labeling of serotonin uptake sites in rat brain by $\left[{ }^{3} \mathrm{H}\right]$ citalopram contrasted to labeling of multiple sites by $\left[{ }^{3} \mathrm{H}\right]$ imipramine. J Pharmacol Exp Ther 242: 364-371.

Deupree JD, Montgomery MD, Bylund DB (2007). Pharmacological properties of the active metabolites of the antidepressants desipramine and citalopram. Eur J Pharmacol 576: 55-60.

Dickinson SL (1990). Alpha2-adrenoceptor antagonism and depression. Drug News Perspect 4: 197-203.

Dunah AW, Standaert DG (2001). Dopamine D1 receptordependent trafficking of striatal NMDA glutamate receptors to the postysynaptic membrane. J Neurosci 21: 5546-5558.
Frazer A (2001). Serotonergic and noradrenergic reuptake inhibitors: prediction of clinical effects from in vitro potencies. J Clin Psychiatry 62: 16-23.

Frazer A, Benmansour S (2002). Delayed pharmacological effects of antidepressants. Mol Psychiatry 7: S23-S28.

Gelenberg AJ, Chesen CL (2000). How fast are antidepressants? J Clin Psychiatry 61: 712-721.

Gould GG, Altamirano AV, Javors MA, Frazer A (2006). A comparison of the chronic treatment effects of venlafaxine and other antidepressants on serotonin and norepinephrine transporters. Biol Psychiatry 59: 408-414.

Gould GG, Pardon MC, Morilak DA, Frazer A (2003). Regulatory effects of reboxetine treatment alone, or following paroxetine treatment, on brain noradrenergic and serotonergic systems. Neuropsychopharmacology 28: 1633-1641.

Hensler JG (2003). Regulation of 5- $\mathrm{HT}_{1 \mathrm{~A}}$ receptor function in brain following agonist or antidepressant administration. Life Sci 72: $1665-1682$.

Hirano K, Kimura R, Sugimoto Y, Yamada J, Uchida S, Kato Y et al (2005a). Relationship between brain serotonin transporter binding, plasma concentration and behavioural effect of selective serotonin reuptake inhibitors. Br J Pharmacol 144: 695-702.

Hirano K, Seki T, Sakai N, Kato Y, Hashimoto H, Uchida S et al (2005b). Effects of continuous administration of paroxetine on ligand binding site and expression of serotonin transporter protein in mouse brain. Brain Res 1053: 154-161.

Horschitz S, Hummerich R, Schloss P (2001). Down-regulation of the rat serotonin transporter upon exposure to a selective serotonin reuptake inhibitor. Neuroreport 12: 2181-2184.

Iceta R, Mesonero JE, Alcalde AI (2007). Effect of long-term fluoxetine treatment on the human serotonin transporter in Caco-2 cells. Life Sci 80: 1517-1524.

Iversen L (2006). Neurotransmitter transporters and their impact on the development of psychopharmacology. $\mathrm{Br} J$ Pharmacol 147: S82-S88.

Jayanthi LD, Samuvel DJ, Ramamoorthy S (2004). Regulated internalization and phosphorylation of the native norepinephrine transporter in response to phorbol esters. Evidence for localization in lipid rafts and lipid raft-mediated internalization. J Biol Chem 279: 19315-19326.

Katz MM, Koslow SH, Frazer A (1996). Onset of antidepressant activity: reexamining the structure of depression and multiple actions of drugs. Depress Anxiety 4: 257-267.

Katz MM, Tekell JL, Bowden CL, Brannan S, Houston JP, Berman $\mathrm{N}$ et al (2004). Onset and early behavioral effects of pharmacologically different antidepressants and placebo in depression. Neuropsychopharmacology 29: 566-579.

Koe BK, Weissman A (1966). p-Chlorophenylalanine: a specific depletory of brain serotonin. J Pharmacol Exp Ther 154: 499-516.

Kozisek ME, Deupree JD, Burke WJ, Bylund DB (2007). Appropriate dosing regimens for treating juvenile rats with desipramine for neuropharmacological and behavioral studies. J Neurosci Methods 163: 83-91.

Kugaya A, Seneca NM, Snyder PJ (2003). Changes in human in vivo serotonin and dopamine transporter availabilities during chronic antidepressant administration. Neuropsychopharmacology 28: 413-420.

Lam RW, Tam EM, Grewal A, Yatham LN (2001). Effects of alphamethyl-para-tyrosine-induced catecholamine depletion in patients with seasonal affective disorder in summer remission. Neuropsychopharmacology 25: S97-S101.

Lapiz MD, Zhao Z, Bondi CO, O’Donnell JM, Morilak DA (2007). Blockade of autoreceptor-mediated inhibition of norepinephrine release by atipamezole is maintained after chronic reuptake inhibition. Int J Neuropsychopharmacol 10: 827-833.

Larsen MB, Elfving B, Wiborg O (2004). The chicken serotonin transporter discriminates between serotonin-selective reuptake 
inhibitors. A species-scanning mutagenesis study. J Biol Chem 279: 42147-42156.

Lau T, Horschitz S, Berger S, Bartsch D, Schloss P (2008). Antidepressant-induced internalization of the serotonin transporter in serotonergic neurons. FASEB J 22: 1702-1714.

Laux G, Volz HP, Moller HJ (1995). Newer and older monoamine oxidase inhibitors: a comparative profile. CNS Drugs 3: 145-148.

Lenox RA, Frazer A (2002). Mechanism of action of antidepressants and mood stabilizers. In: Davis KL, et al, (eds). Neuropsychopharmacology: The Fifth Generation of Progress. American College of Neuropsychopharmacology: Nashville, TN. pp 1139-1163.

Lesch PK, Aulakh CS, Wolozin BL, Tolliver TJ, Hill JL, Murphy DL (1993). Regional brain expression of serotonin transporter mRNA and its regulation by reuptake inhibiting antidepressants. Mol Brain Res 17: 31-35.

Lin JW, Wyszynski M, Madhavan R, Sealock R, Kim JU, Sheng M (1998). Yotiao, a novel protein of neuromuscular junction and brain that interacts with specific splice variants of NMDA receptor subunit NR1. J Neurosci 18: 2017-2027.

Lopez JF, Chalmers DT, Vazquez DM, Watson SJ, Akil H (1994). Serotonin transporter mRNA in rat brain is regulated by classical antidepressants. Biol Psychiatry 35: 287-290.

López-Muñoz F, Alamo C, Juckel G, Assion HJ (2007). Half a century of antidepressant drugs: on the clinical introduction of monoamine oxidase inhibitors, tricyclics, and tetracyclics. Part I: monoamine oxidase inhibitors. J Clin Psychopharmacol 27: $555-559$.

Millan MJ (2006). Multi-target strategies for the improved treatment of depressive states: conceptual foundations and neuronal substrates, drug discovery and therapeutic application. Pharmacol Ther 110: 135-370.

Millan MJ, Gobert A, Lejeune F, Newman-Tancredi A, Rivet JM, Auclair A (2001). S33005, a novel ligand at both serotonin and norepinephrine transporters: II. Behavioral profile in comparison with venlafaxine, reboxetine, citalopram, and clomipramine. J Pharmacol Exp Ther 298: 565-580.

Millan MJ, Gobert A, Rivet JM, Adhumeau-Auclair A, Cussac D, Newman-Tancredi A et al (2000). Mirtazapine enhances frontocortical dopaminergic and corticolimbic adrenergic, but not serotonergic, transmission by blockade of alpha2-adrenergic and serotonin2C receptors: a comparison with citalopram. Eur J Neurosci 12: 1079-1095.

Miller HL, Delgado PL, Salomon RM, Berman R, Krystal JH, Heninger GR et al (1996a). Clinical and biochemical effects of catecholamine depletion on antidepressant-induced remission of depression. Arch Gen Psychiatry 53: 117-128.

Miller HL, Delgado PL, Salomon RM, Heninger GR, Charnery DS (1996b). Effects of alpha-methyl-para-tyrosine (AMPT) in drug-free depressed patients. Neuropsychopharmacology 14: 151-157.

Mongeau R, Blier P, de Montigny C (1993). In vivo electrophysiological evidence for tonic activation by endogenous noradrenaline of alpha $\mathrm{a}_{2}$-adrenoceptors on 5-hydroxytryptamine terminals in the rat hippocampus. Naunyn Schmiedebergs Arch Pharmacol 347: 266-272.

Morilak DA, Frazer A (2004). Antidepressants and brain monoaminergic systems: a dimensional approach to understanding their behavioral effects in depression and anxiety disorders. Int $J$ Neuropsychopharmacol 7: 193-218.

Nelson JC, Mazure CM, Jatlow PI, Bowers Jr MB, Price LH (2004). Combining norepinephrine and serotonin reuptake inhibition mechanisms for treatment of depression: a double-blind, randomized study. Biol Psychiatry 56: 535-546.

O’Donnell JM, Marek GJ, Seiden LS (2005). Antidepressant effects assessed using behavior maintained under a differentialreinforcement-of-low-rate (DRL) operant schedule. Neurosci Biobehav Rev 29: 785-798.
O’Donnell JM, Seiden LS (1984). Altered effects of desipramine on operant performance after 6-hydroxydopamine-induced depletion of brain dopamine or norepinephrine. J Pharmacol Exp Ther 229: 629-635.

O'Leary OF, Bechtholt AJ, Crowley JJ, Hill TE, Page ME, Lucki I (2007). Depletion of serotonin and catecholamines block the acute behavioral response to different classes of antidepressant drugs in the mouse tail suspension test. Psychopharmacology 192: $357-371$.

Ordway GA, Gambarana C, Tejani-Butt SM, Areso P, Hauptmann M, Frazer A (1991). Preferential reduction of binding of 125Iiodopindolol to beta-1 adrenoceptors in the amygdala of rat after antidepressant treatments. J Pharmacol Exp Ther 257: 681-690.

Owens MJ, Morgan WN, Plott SJ, Nemeroff CB (1997). Neurotransmitter receptor and transporter binding profile of antidepressants and their metabolites. J Pharmacol Exp Ther 283: 1305-1322.

Page ME, Detke MJ, Dalvi A, Kirby LG, Luckii I (1999). Serotonergic mediation of the effects of fluoxetine, but not desipramine, in the rat forced swimming test. Psychopharmacology 147: 162-167.

Page ME, Lucki I (2002). Effects of acute and chronic reboxetine treatment on stress-induced monoamine efflux in the rat frontal cortex. Neuropsychopharmacology 27: 237-247.

Paxinos G, Watson C (1998). The Rat Brain in Stereotaxic Coordinates, 4th edn. Academic Press: San Diego.

Porsolt RD, Le PM, Jalfre M (1977). Depression: a new animal model sensitive to antidepressant treatments. Nature 266: 730 732.

Qian Y, Galli A, Ramamoorthy S, Risso S, DeFelice LJ, Blakely RD (1997). Protein kinase C activation regulates human serotonin transporters in HEK-293 cells via altered cell surface expression. J Neurosci 17: 45-57.

Rossi DV, Valdez M, Gould GG, Hensler JG (2005). Chronic administration of venlafaxine fails to attenuate 5-HT1A receptor function at the level of receptor-G protein interaction. Int $J$ Neuropsychopharmacol 8: 1-14.

Salomon RM, Miller HL, Delgado PL, Charney D (1993). The use of tryptophan depletion to evaluate central serotonin function in depression and other neuropsychiatric disorders. Int Clin Psychopharmacol (Suppl) 2: 41-46.

Scates AC, Doraiswamy PM (2000). A selective norepinephrine reuptake inhibitor for the treatment of depression. Ann Pharmacother 34: 1302-1312.

Schmid JA, Just H, Sitte HH (2001). Impact of oligomerization on the function of the human serotonin transporter. Biochem Soc Trans 29: 732-736.

Smith PK, Krohn PI, Hermanson GT, Mallia AK, Gartner FH, Provenzano MD et al (1985). Measurement of protein using bicinchoninic acid. Anal Biochem 150: 76-85.

Sung U, Blakely RD (2007). Calcium-dependent interactions of the human norepinephrine transporter with syntaxin 1A. Mol Cell Neurosci 34: 251-260.

Sung U, Jennings JL, Link AJ, Blakely RD (2005). Proteomic analysis of human norepinephrine transporter complexes reveals associations with protein phosphatase $2 \mathrm{~A}$ anchoring subunit and 14-3-3 proteins. Biochem Biophys Res Commun 333: 671-678.

Szot P, Ashliegh EA, Kohen R, Petrie E, Dorsa DM, Veith R (1993). Norepinephrine transporter mRNA is elevated in the locus ceruleus following short- and long-term desipramine treatment. Brain Res 618: 308-312.

Tanaka E (1998). Clinically important pharmacokinetic drug-drug interactions: role of cytochrome P450 enzymes. J Clin Pharm Ther 23: 403-416.

Tejani-Butt SM, Brunswick DJ, Frazer A (1990). ${ }^{3} \mathrm{H}$-nisoxetine: a new radioligand for norepinephrine uptake sites in brain. Eur $J$ Pharmacol 191: 239-243. 
Thakker DR, Natt F, Hüsken D, van der Putten H, Maier R, Hoyer D et al (2005). siRNA-mediated knockdown of the serotonin transporter in the adult mouse brain. Mol Psychiatry 10: $782-789$.

Thase ME, Trivedi MH, Rush AJ (1995). MAOIs in the contemporary treatment of depression. Neuropsychopharmacology 12: $185-219$.

Versiani M, Mehilane L, Gaszner P, Arnaud-Castiglioni R (1999). Reboxetine, a unique selective NRI, prevents relapse and recurrence in long-term treatment of major depressive disorder. J Clin Psychiatry 60: 400-406.

Weinshenker D, White SS, Javors MA, Palmiter RD, Szot P (2002). Regulation of norepinephrine transporter abundance by catecholamines and desipramine in vivo. Brain Res 946: 239-246.

White KJ, Walline CC, Barker EL (2005). Serotonin transporters: implications for antidepressant drug development. AAPS J 7: E421-E433.

Wong EH, Sonders MS, Amara SG, Tinholt PM, Piercey MF, Hoffmann WP et al (2000). Reboxetine: a pharmacologically potent, selective, and specific norepinephrine reuptake inhibitor. Biol Psychiatry 47: 818-829.

Wyszynski M, Kharazia V, Shanghvi R, Rao A, Beggs AH, Craig AM et al (1998). Differential regional expression and ultrastructural localization of alpha-actinin-2, a putative NMDA receptor anchoring protein, in rat brain. J Neurosci 18: 1383-1392.

Xie T, Tong L, McLane MW, Hatzidimitriou G, Yuan J, McCann U et al (2006). Loss of serotonin transporter protein after MDMA and other ring-substituted amphetamines. Neuropsychopharmacology 31: 2639-2651.

Zhang HT, Huang Y, Masood A, Stolinski LR, Li Y, Zhang L et al (2008). Anxiogenic-like behavioral phenotype of mice deficient in phosphodiesterase 4B (PDE4B). Neuropsychopharmacology 33: 1611-1623.

Zhao Z, Baros AM, Zhang HT, Lapiz MD, Bondi CO, Morilak DA et al (2008). Norepinephrine transporter regulation mediates the long-term behavioral effects of the antidepressant desipramine. Neuropsychopharmacology. print copy in press (originally published online Apr. 16, 2008 at http://www.nature.com/npp/ journal/vaop/ncurrent/abs/npp200845a.html).

Zhu MY, Blakely RD, Apparsundaram S, Ordway GA (1998). Down-regulation of the human norepinephrine transporter in intact 293-hNET cells exposed to desipramine. J Neurochem 70: $1547-1555$

Zhu MY, Kim CH, Hwang DY, Baldessarini RJ, Kim KS (2002). Effects of desipramine treatment on norepinephrine transporter gene expression in the cultured SK-N-BE(2)M17 cells and rat brain tissue. J Neurochem 82: 146-153.

Zhu MY, Ordway GA (1997). Down-regulation of norepinephrine transporters on PC12 cells by transporter inhibitors. J Neurochem 68: 134-141.

Zhu MY, Wang WP, Baldessarini RJ, Kim KS (2005). Effects of desipramine treatment on tyrosine hydroxylase gene expression in cultured neuroblastoma cells and rat brain tissue. Brain Res Mol Brain Res 133: 167-175. 